\title{
DISCRETE POLARISATION WITH AN APPLICATION TO THE DETERMINANTS OF GENOCIDES*
}

\author{
Jose G. Montalvo and Marta Reynal-Querol
}

\begin{abstract}
Inequality and polarisation are two different measures of heterogeneity. As in the case of inequality, the measurement of polarisation was initially developed in the context of a continuous dimension (income). However, in many important dimensions, like ethnicity, there are no available measures of distance across ethnic groups and individuals are mostly separated by the dichotomous perception 'we versus they'. In this article we analyse the theoretical properties of a measure of polarisation based on classifications (discrete polarisation) instead of continuous distances across groups. The second part of the article presents an application of the index of discrete ethnic polarisation to the explanation of genocides.
\end{abstract}

In the twentieth century, genocides and state mass murder have killed more people than have all wars.

Institute for the Study of Genocide. International Association of Genocide Scholars.

The concept of polarisation has been used frequently in political science and economics, although its precise conceptualisation has turned out to be evasive and difficult. For this reason many authors used it in a very imprecise, and sometimes conflicting, fashion. The contributions of Esteban and Ray (1994) and Wolfson (1994) ${ }^{1}$ represent the first attempts to provide a precise definition of polarisation. These recent definitions explain why the empirical measurement of different dimensions of polarisation is a very recent phenomenon, opposite to the somehow related concept of inequality which has generated thousands of contributions on measurement.

The concept of polarisation was initially developed in the context of a continuous dimension, in particular income, which defined the 'closeness' of the characteristics of the individuals. Esteban and Ray (1994) present the properties of a precise axiomatisation of a class of polarisation measures based on distances in the real line. ${ }^{2}$ However, in many important dimensions (like ethnicity or religion), there is no information on a continuous variable to measure distances across groups, or the 'distances' have to be discretised, and there is no precise information on the latent variable used for the

* We are grateful for comments by A. Alesina, T. Besley, P. Collier, J. Fearon, D. Ray, two anonymous referees and, especially, A. Villar. We thank the participants of seminars at the World Bank, Universitat Pompeu Fabra, Institut Europeu de la Mediterranea, Toulouse, Brown University, the European Economic Association Meetings and the Winter Meetings of the Econometric Society. Reynal-Querol has received funding from the European Research Council under the European Community's Seventh Framework Programme (FP7/2007-2013)/ERC grant agreement n. 203576. Financial support from the Xarxa CREA, grants SEJ2007-64340/ECON and SEJ2006-10974/ECON from the Ministerio de Educacion y Ciencia are gratefully acknowledged. The authors acknowledge also the support of the Barcelona GSE Research Network and the Government of Catalonia.

${ }^{1}$ In fact Wolfson (1994) emphasises the difference between polarisation and inequality and develops a theoretical measure of the former that can be interpreted using the Lorenz curve.

${ }^{2}$ Empirical applications of this measure can be found in Gradin (2000) and Duclos et al. (2004). Anderson (2004) considers measures of polarisation in terms of stochastic dominance. Keefer and Knack (2002) have argued that income-based measures of polarisation are similar to their corresponding Gini coefficients. 
discretisation. In this article we discuss the theoretical properties of a class of measures of discrete polarisation based on classifications instead of continuous distances. We also show that it is empirically quite different from the analogous inequality measure (fractionalisation). There are many reasons that favour the use of a discrete metric to construct the index of ethnic or religious polarisation. ${ }^{3}$ First, there are no measures of distance across ethnic (religious) groups available and generally accepted. ${ }^{4}$ The measure of the 'distance' across ethnic groups is much more controversial than the identification of the list of ethnic groups. Second, the measurement of distances across groups may generate a larger measurement error than the 'belong/does not belong to' criterion. Third, if the distance across groups is measured using the strength of the sentiment of identity or political relevance then there is an important endogeneity problem. At the end we will be explaining conflict using conflict as the explanatory variable, since the sentiment of identity is high when there is conflict. Fourth, as argued by Duclos et al. (2004), 'there are many interesting instances in which individuals are interested only in the dichotomous perception Us/They'. We believe the case of ethnic (religious) groups is a important example of this situation. Finally, the 'distance' across groups is most likely a function of polarisation. It is reasonable to argue that in a very polarised society the distance across groups will be large, in the sense of generating a strong sentiment of identity and opposition to the other groups. If this is the case the index of discrete polarisation is also capturing distances in a way.

Some authors ${ }^{5}$ have applied Esteban and Ray's $(1994)^{6}$ index to data on groups, without information on distances, assuming that the same properties of the original measure extend to the 'belong-do not belong' situation. The first objective of this article is to emphasise the fact that with discrete distances the mechanical application of that index is not appropriate. This is not a minor point since the empirical calculation of any the index of discrete polarisation depends on the choice of the parameter in the set of feasible degrees of polarisation sensitivity.

The second part of the article analyses the effect of discrete ethnic polarisation on the probability of genocides. Recently, many academic economists have turned to the study of conflict and its main determinants. In empirical applications, civil wars are the variable most frequently used to proxy for conflict. However, genocide, which is one of the most violent and bloody forms of social violence, has not receive much attention, even though it results in more deaths than civil wars. Since World War II there have been nearly 50 instances of genocide and political mass murder and these episodes have cost the lives of at least 12 million combatants, and as many as 22 million noncombatants. Those are more than all the victims of internal and international wars since $1945 .{ }^{7}$ We use data on genocides because, in principle, they are more appropriate for testing the relevance of (ethnic) polarisation for the analysis of extreme violence.

\footnotetext{
3 This comment also applies to many other characteristics that cannot be ordered in the real line (country of birth, immigration status etc.).

${ }^{4}$ Fearon (2003) presents a proposal to measure 'cultural fractionalisation' based on the calculation of resemblance factors.

${ }^{5}$ For instance Aghion et al. (2004), Collier and Hoeffler (2004) or Alesina et al. (2003).

${ }^{6}$ From now on ER94.

7 See the State Failure Task Force.
}

(C) The Author(s). Journal compilation (C) Royal Economic Society 2008 
Genocides are characterised by the extermination of members of a target group, a phenomenon that does not always happen during a civil war. Since ethnic disputes are usually very violent it is reasonable to infer that ethnicity may have an important effect on the probability of genocides. However, recent papers on the determinants of genocides, and civil wars in general, have found no evidence of the effect of ethnic fractionalisation. ${ }^{8}$ These findings have led some researchers to dismiss ethnicity as a potential source of extreme violence, in clear contrast with traditional theories. However, the properties of discrete polarisation discussed in this article suggest that the higher is the level of violence the more relevant is the effect of ethnic polarisation. In this article we find that ethnic heterogeneity is a statistically significant determinant of the probability of a genocide if we use an index of discrete ethnic polarisation instead of ethnic fractionalisation. We also find that ethnic polarisation increases the likelihood of genocides more than the probability of a civil war.

A particular index of the general family of discrete polarisation measures, the RQ, was used by Montalvo and Reynal-Querol (2005a) in their empirical study of the causes of civil wars. The final message of that paper was strictly empirical: the RQ index is a significant explanatory variable for the incidence of civil wars. In the current article we present three basic contributions: first of all, we provide a precise mathematical characterisation of a class of discrete polarisation measures and characterise the properties of the particular index (RQ) theoretically. Secondly, we prove that the only polarisation sensitivity compatible with reasonable properties of polarisation is $\alpha=1$. We consider this to be an important contribution since many authors (as we mentioned before) have wrongly understood that they can use any degree of polarisation sensitivity compatible with the ER94 index, $(0-\approx 1.6]$, to construct indices of discrete polarisation. Finally, as we argue in the theory part, discrete polarisation should be more relevant the more intense is the conflict. Genocides are a perfect example since they represent the most violent form of conflict. The third original contribution of this article is to show that the contribution of ethnic polarisation to the likelihood of a conflict increases with the intensity of the conflict.

The outline of the article is the following. Section 1 introduces the concept of discrete polarisation and discusses its theoretical properties. Section 2 analyses the empirical performance of discrete ethnic polarisation in the explanation of genocides. Section 3 concludes.

\section{A Class of Discrete Polarisation Measures}

Traditionally the study of the impact of ethnicity on growth or civil wars has rested on the construction of indices of fractionalisation, even though most of the theories refer to 'polarised societies. .9 Several authors have interpreted the finding of a negative relationship between ethnic fractionalisation and growth as evidence of a high probability of conflict in very heterogeneous societies. However, the empirical evidence on the direct

\footnotetext{
${ }^{8}$ For instance, Harff (2003) finds that none of the numerous indicators of ethnic and religious cleavages was significant. Only one variable, weakly connected with ethnicity (political elite based on an ethnic minority), was statistically significant.

${ }^{9}$ Easterly and Levine (1997).
} 
relationship between fractionalisation and civil wars is at most very weak. ${ }^{10}$ We argue that the reason why ethnicity does not seem to have any impact on conflict is the use of the index of fractionalisation. Reynal-Querol (2002) proposed an index of ethnic heterogeneity, $R Q$, that tried to capture polarisation instead of fractionalisation

$$
R Q=1-\sum_{i=1}^{N}\left(\frac{1 / 2-\pi_{i}}{1 / 2}\right)^{2} \pi_{i}
$$

The original purpose of this index was to capture how far the distribution of the ethnic groups is from the $(1 / 2,0,0, \ldots 0,1 / 2)$ distribution (bipolar), which represents the highest level of polarisation. ${ }^{11}$ There was no analysis of theoretical properties or implications. Montalvo and Reynal-Querol (2005a) show some properties of the RQindex but their paper is basically empirical, showing that if we measure ethnic heterogeneity in terms of bipolarity then ethnicity is key to explain the probability of civil wars. ${ }^{12}$

One of the objectives of our current article is to provide a theoretical foundation for the family of discrete polarisation measures given the lack of development of the theory. ER94 provide a particular conceptualisation for polarisation, emphasising the difference between inequality and polarisation. What do they mean by polarisation? A population of individuals may be grouped according to some vector of characteristics into 'clusters' such that each cluster is similar in terms of the attributes of its members, but different clusters have members with 'dissimilar' attributes. Such a society is polarised even if the measurement of inequality may be low.

By using three axioms, Esteban and Ray (1994) narrow down the class of allowable polarisation measures to only one measure, $P$, with the following form

$$
P=k \sum_{i=1}^{N} \sum_{j=1}^{N} \pi_{i}^{1+\alpha} \pi_{j}\left|y_{i}-y_{j}\right|
$$

for some constants $k>0$ and $\alpha \in\left(0, \alpha^{*}\right]$ where $\alpha^{*} \simeq 1.6$. When $\alpha=0^{13}$ and $k=1$ this polarisation measure is precisely the Gini coefficient. Therefore the fact that the share of each group is raised to the power $1+\alpha$, which exceeds one, is what makes the polarisation measure significantly different from inequality measures. The parameter $\alpha$ can be treated as the degree of 'polarisation sensitivity'.

In the case of ethnic diversity the identity of the groups is less controversial than the 'distance' between different ethnic groups, which is much more difficult to measure than income or wealth. Then, it is reasonable to treat the 'distance' across groups, $\delta(.,$.$) ,$ as generated by a discrete metric (1-0). If we want to measure ethnic diversity, the distance between ethnic groups may be a very difficult concept to measure. If we consider the criteria 'belongs' or 'does not belong' to an ethnic (religious) group, instead of the distance, then we should substitute the Euclidean metric $\delta\left(y_{i}, y_{j}\right)=$ $\left|y_{i}-y_{j}\right|$, by a discrete metric

\footnotetext{
10 See for instance Collier and Hoeffler (2004).

11 See also Reynal-Querol (2001).

12 Montalvo and Reynal-Querol (2005b) show that the index RQ can be derived from a rent seeking model of conflict.

${ }^{13}$ Strictly speaking for $\alpha=0$ this is not an index of polarisation.
}

(C) The Author(s). Journal compilation (C) Royal Economic Society 2008 


$$
\begin{aligned}
\delta\left(y_{i}, y_{j}\right) & =0 & & \text { if } i=j \\
& =1 & & \text { if } i \neq j .
\end{aligned}
$$

In addition, any classification of ethnic groups implies a criterion for transforming the differences of the characteristics of ethnic groups into a discrete decision rule (for instance, same family-different family). For example, following the classification of the World Christian Encyclopedia (Barret, 1982), the ethnic subgroup of the Luba, the Mongo and the Nguni belong to the Bantu ethnolinguistic group. The Akan, the Edo and the Ewe belong to the Kwa ethnolinguistic group. This implies that the 'cultural distance' (defined informally by the Encyclopedia) between the subgroups of the Bantu group is smaller than the difference between one subgroup of the Bantu family and one of the Kwa family. In terms of a discrete metric, if we use the family classification as the base for the difference across groups, this means that the subgroup of the Bantu family are inside the ball of radius $r$ that defines the discrete metric while the subgroups in the family Kwa are outside that ball. Therefore, any classification involves implicitly a concept and a measure of 'distance' that is discretised.

The class of indices of discrete polarisation, $D P$, can be described as

$$
D P(\alpha, k)=k \sum_{i=1}^{N} \sum_{j \neq i} \pi_{i}^{1+\alpha} \pi_{j}
$$

which depends on the values of the parameters $\alpha$ and $k_{.}{ }^{14}$

Embedding a discrete metric into ER's polarisation measure $P$ alters the original formulation of the index as a polarisation measure. It is known that the discrete metric and the Euclidean metric are not equivalent in $R$. For this reason the apparently minor change of the metric implies that the discrete polarisation measure does not satisfy the properties of polarisation for all the range of possible values of $\alpha$ anymore. Therefore, for each possible $\alpha$, we have a different shape for the DP index. The question we want to analyse is the following: what is the admissible set of values for the coefficient $\alpha$ if the DP measure has to satisfy the basic properties of polarisation? ${ }^{15}$ Our objective is, therefore, to check if the basic properties of polarisation are satisfied by what we call discrete polarisation. In this Section we also show that for $\alpha=1$ and $k=4$ the DP index has the usual properties of a polarisation measure bounded between 0 and 1 . This particular case is the RQ index of polarisation.

The definition of polarisation as a concept closely related to social tensions implies several characteristics. ER94 define the conditions imposed by polarisation using the interaction between changes in the Euclidean distance of groups (for instance in terms

\footnotetext{
${ }^{14}$ By analogy, what we call a discrete Gini index is a discrete polarisation measure with $\alpha=0$ and $k=1$ (also called index of fractionalisation or FRAC). We distinguish FRAC $(D P(0, k))$ from the general discrete polarisation $(D P(\alpha>0, k))$ even though the former is a particular case of the $D P$ family. As we argued before, the fact that $\alpha>0$ is the basic attraction of polarisation measures versus inequality indices.

${ }^{15}$ Notice that this is somehow different from the original objective of Esteban and Ray (1994). They characterise the general form of a polarisation measure in a particular family using several axioms. This implies a limit for the parameter $\alpha$ that cannot be larger than 1.6, but also a special form for any polarisation measure. Our objective in this Section is to check if the basic properties of polarisation are satisfied by what we call discrete polarisation. However we are not claiming that the DP index is the only possible form for a polarisation measure based on discrete distances.
}

(C) The Author(s). Journal compilation (c) Royal Economic Society 2008 
of income) and their relative size. We are going to redefine those conditions in terms of groups size only, since we are not using distances across groups. We work with three groups, since this is the minimum number of groups that make the measure of polarisation different from the index of fractionalisation. An index of discrete polarisation should have two basic properties. The first property (PR1) is that if we join the two smallest groups polarisation should increase. ${ }^{16}$ The second property (PR2) is that any new distribution formed by shifting probability mass from one group equally to the other two groups must increase polarisation. ${ }^{17}$ We can show formally that the only DP measure that satisfies the two properties exposed above is the one with a value of $\alpha=1$. Let us restate these two properties ${ }^{18}$ formally and derive the implications with respect to the values of $\alpha$. Define $\pi_{1}=p, \pi_{2}=q$ and $\pi_{3}=r$.

Property 1. If there are three groups of sizes, $p$, $q$, and $r$, and $p>q$ and $q \geq r$, then if we merge the two smallest groups into a new group, $\tilde{q}$, the new distribution is more polarised than the original one. That is, $\operatorname{POL}(p, q, r)<\operatorname{POL}(p, \tilde{q})$ where $\tilde{q}=q+r$.

We define $\operatorname{POL}(x)$ as the proper index of polarisation when $x=(p, q, r)$. Property 1 states that when we join the two smallest groups the index of polarisation should increase.

THeorem 1. DP $(\alpha, k)$ satisfies property 1 if and only if $\alpha \geq 1$. (see the proof in the Appendix)

As we argued before we need $\alpha \geq 1$ to have a DP measure that satisfies property 1 . We can prove that this is the case for any number of groups and not only three.

Property $1 b$. Suppose that there are two groups with size $\pi_{1}$ and $\pi_{2}$. Take any one group and split it into $m \geq 2$ groups in such a way that $\pi_{1}=\tilde{\pi}_{1} \geq \tilde{\pi}_{i} \forall_{i=2, . . n+1}$., where $\tilde{\pi}$ is the new vector of population sizes, and clearly $\sum_{i=2}^{n+1} \tilde{\pi}_{i}=\pi_{2}$. Then polarisation under $\tilde{\pi}$ is smaller than under $\pi$.

Theorem 2. The $D P(\alpha, k)$ measure satisfies property $1 b$ if and only if $\alpha \geq 1$. (see the proof in the Appendix)

Another property of polarisation measures is that they attain their maximum at a bipolar symmetric distribution. We can generalise the result using the following lemma.

Lemma 1. The $D P(\alpha, k)$ index attains its maximum at a bipolar symmetric distribution if $\alpha \geq 1$. (see the proof in the Appendix).

Property 2 can be stated formally in the following way.

Property 2: Assume that there are three groups of sizes $p, q, p$. Then if we shift mass from the $q$ group equally to the other two groups, polarisation increases. That is, $P O L(p, q, p)<$ $\operatorname{POL}(p+x, q-2 x, p+x) .^{19}$

16 This property corresponds basically with axioms 1 and 2 in Esteban and Ray (1994).

17 This is the analogy for discrete distances of axiom 3 in ER94.

18 Notice that, in our case, we do not use the term 'axiom' since we are not interested in describing and narrowing down a general class of discrete polarisation measures. We only want to check if the DP measure proposed in this article satisfies those properties.

${ }^{19}$ This property corresponds to axiom 3 in ER94.

(C) The Author(s). Journal compilation (C) Royal Economic Society 2008 
THEOREM 3. The only $D P(\alpha, k)$ measure that satisfy property 2 for any distribution is the one such that $\alpha=1$ (see proof in Appendix).

Corollary. The only family of DP measures that satisfies Properties 1 and 2 is the one with $\alpha=1, D P(1, k)$.

If we fix $\alpha=1$, and choose $k=4$ (which makes the range of the index $D P(1, k)$ lie between 0 and 1) then we obtain the $R Q$ index

$$
\begin{aligned}
D P(1,4) & =4 \sum_{i=1}^{N} \sum_{j \neq i} \pi_{i}^{2} \pi_{j}=4 \sum_{i=1}^{n} \pi_{i}^{2}\left(1-\pi_{i}\right)=\sum_{i=1}^{n} \pi_{i}\left[1-\left(1+4 \pi_{i}^{2}-4 \pi_{i}\right)\right] \\
& =\sum_{i=1}^{n} \pi_{i}-4 \sum_{i=1}^{n}\left(0.5-\pi_{i}\right)^{2} \pi_{i}=1-\sum_{i=1}^{N}\left(\frac{0.5-\pi_{i}}{0.5}\right)^{2} \pi_{i}=R Q .
\end{aligned}
$$

Figure 1 shows the graph of the fractionalisation index (FRAC) and the $R Q$ index of polarisation as a function of the number of groups when all of them have the same size. The index of fractionalisation is defined by the expression

$$
F R A C=1-\sum_{i=1}^{N} \pi_{i}^{2}=\sum_{i=1}^{N} \pi_{i}\left(1-\pi_{i}\right)
$$

where $\pi_{i}$ is the proportion of people that belong to the ethnic group $i$ and $N$ is the number of groups. This index has a simple interpretation as the probability that two randomly selected individuals from a given country will not belong to the same ethnic group and it increases monotonically with the number of groups. By contrast, the $R Q$ index reaches a maximum when there are two groups. ${ }^{20}$

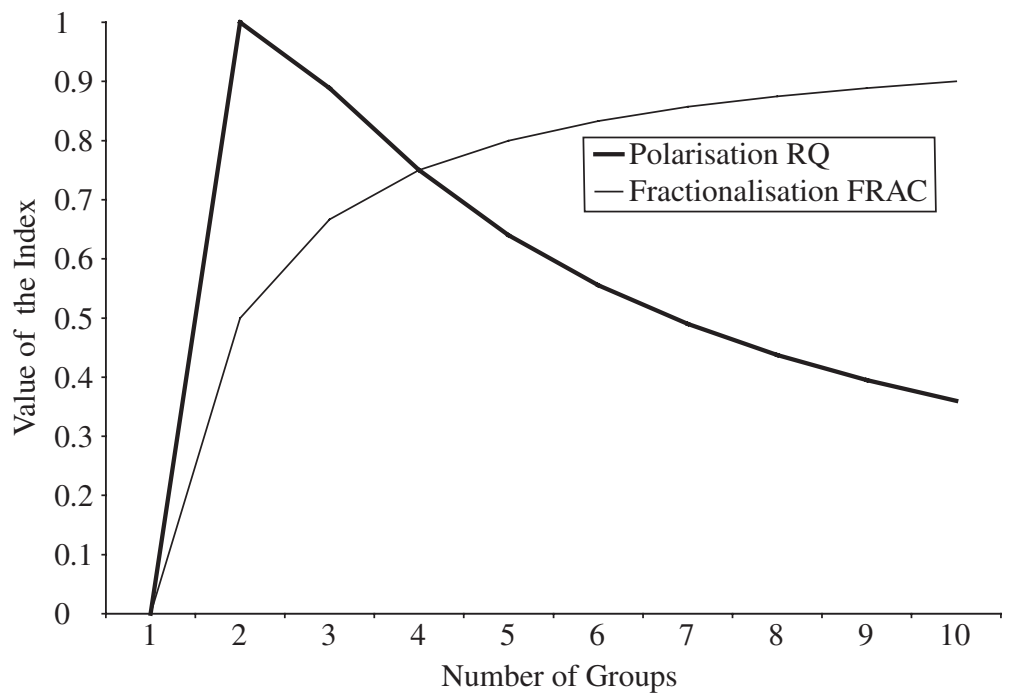

Fig. 1. Fractionalisation and Polarisation as a Function of the Number of Groups (same size)

${ }^{20}$ Certainly the number of groups that maximise conflict in the context of a rent seeking contest is model specific. However the original justification for polarisation measures (Esteban and Ray, 1994) is to produce an index that obtains a maximum for the distribution $(1 / 2,0,0, \ldots, 0,1 / 2)$.

(C) The Author(s). Journal compilation (C) Royal Economic Society 2008 
The simplest way to look at the implications of different choices of parameters for the discrete polarisation measures is to describe the shape of different surfaces using several examples. Figures 2 to 5 show the shape of the index DP as a function of $\alpha$ in the case of three groups. ${ }^{21}$ Figure 2 corresponds to the case of $\alpha=0$, which is the index of fractionalisation. Figure 3 represents the index of discrete polarisation when $\alpha=1$, which corresponds to the RQ index. Figures 4 and 5 present the surfaces generated by values of $\alpha$ equal to 0.5 and 1.5, respectively. A first look at these Figures shows that we can classify them in two groups in terms of the location of their respective maxima. In particular the surfaces presented in Figures 2 and 4 reach a maximum when all the groups have the same size while in Figures 3 and 5 the maximum is located at the bimodal distribution where two groups have equal size (0.5). In fact the functions with $\alpha<1$ can be considered as variations of the fractionalisation index while the functions with $\alpha \geq 1$ are variations of the polarisation index.

The base of Figures 2 to 5 can be interpreted as a probability triangle, where each point describes a vector of probabilities $\left(\pi_{1}, 1-\pi_{1}-\pi_{3}, \pi_{3}\right)$. We can represent the two properties of polarisation in terms of movement on this triangle. Figure $6 a$ shows movement in the probability triangle that satisfies Property 1 . Starting at point $Y_{0}$ $(0.25,0.25,0.5)$ movement towards point $\mathrm{Y}_{1}(0,0.5,0.5)$ should increase polarisation by PR1 since we are joining the two smallest groups into one larger group. Looking at Figure 2, the index of fractionalisation $(\alpha=0)$ and at Figure $4(\alpha=0.5)$, we realise that in those surfaces the movement from $Y_{0}$ to $Y_{1}$ implies a decrease of the index and, therefore they do not satisfy PR1. For $\alpha=1$ and $\alpha=1.5$ the movement from $Y_{0}$ toward $Y_{1}$ implies an increase in polarisation as stated by PR1. Figure $6 b$ depicts

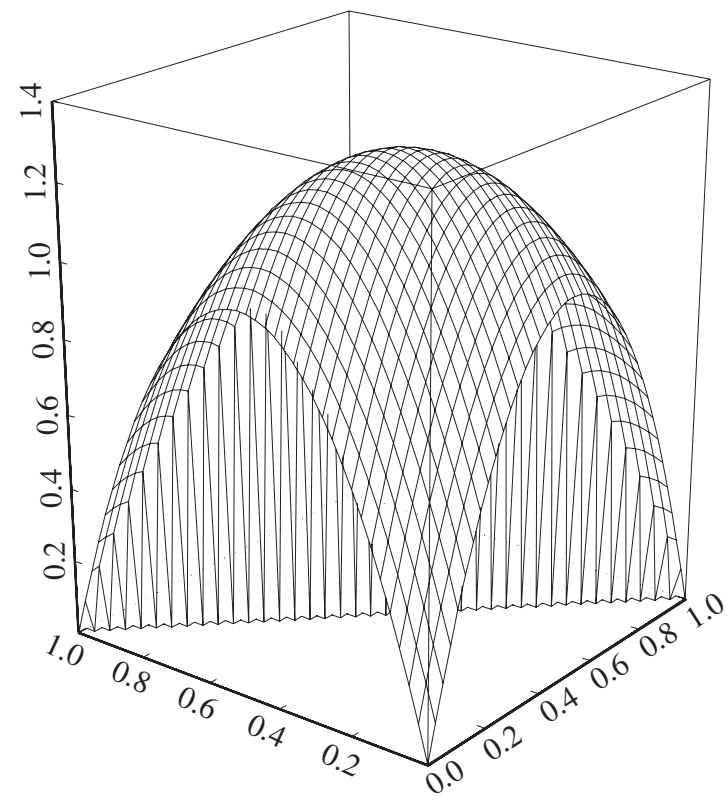

Fig. 2. Index of Fractionalisation or Discrete Polarisation with $\alpha=0$

21 The parameter $k$, which is just a scale factor, is fixed to 4 in all the cases.

(C) The Author(s). Journal compilation (C) Royal Economic Society 2008 


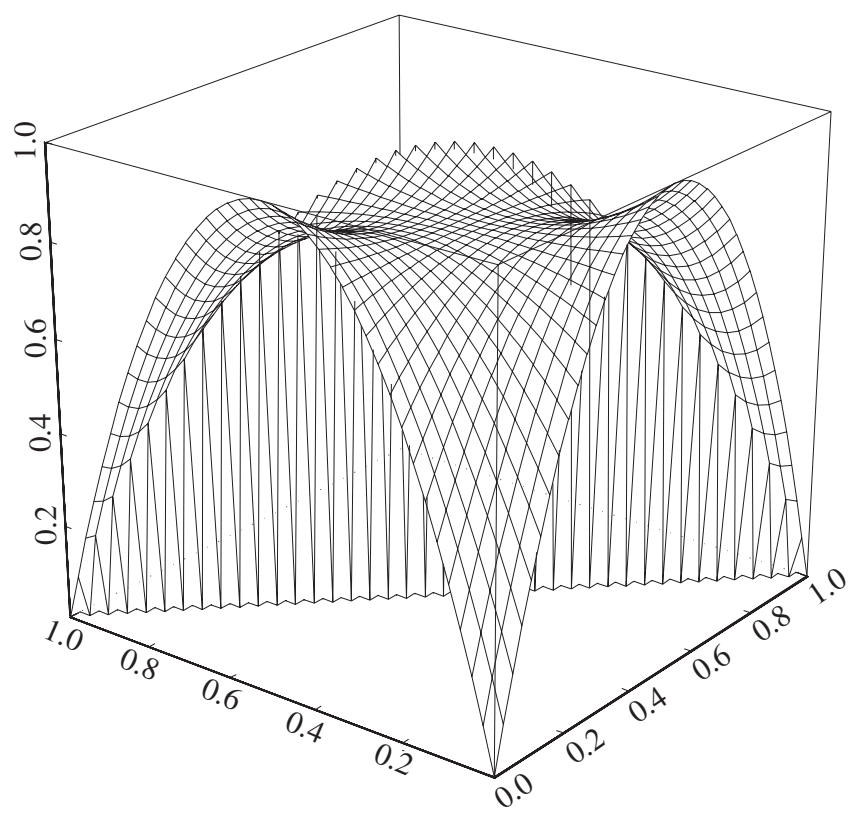

Fig. 3. $R Q$ Index or Discrete Polarisation with $\alpha=1$

movement from $\mathrm{Z}_{0}(0,1,0)$ toward $\mathrm{Z}_{1}(0.5,0,0.5)$, where the mass of group 2 is shifted equally to the other two groups ( 1 and 3 ). By property 2 any movement in this direction should generate an increase in polarisation. Again we can easily see that the surfaces of Figures 2 and 4 do not satisfy PR2 since this movement implies first an increase of the index and then a decrease. The surface in Figure 3, corresponding to $\alpha=1$, satisfies PR2. However, and opposite to what happened in the case of property 1, the surface in Figure $5(\alpha=1.5)$ fails to show a monotonic increase in polarisation in the movement from $\mathrm{Z}_{0}$ toward $\mathrm{Z}_{1}$.

We can see this effect more clearly in Figure 7 where we depict the two dimensional plane generated by cutting the surfaces along the line from $\mathrm{Z}_{0}$ to $\mathrm{Z}_{1}$. The $\mathrm{X}$-axis represents the equal-sized transfer from group 2 to groups 1 and 3 . The Y-axis represents the value of the index. For $\alpha=0.5$ we can see that the index increases until a transfer of $1 / 3$ and then decreases. For $\alpha=1.5$ we see that the index increases and then decreases, hitting a local minimum at $1 / 3$ and increasing again after that point. Finally for $\alpha=1$ we see that the index increases over the whole range with an inflection point at a transfer equal to $1 / 3$. Therefore from this informal discussion of four examples we see that only when $\alpha=1$, which is equivalent to the RQ index, the discrete polarisation measure satisfies both properties.

The previous results show that the range of suitable values of polarisation sensitivity in a measure based on Euclidean distances cannot be translated directly to a measure based on discrete distances. However, several authors have constructed empirical measures of discrete polarisation 'over the range proposed by Esteban and Ray (1994)'. Aghion et al. (2004) construct an index of discrete polarisation where the parameter 


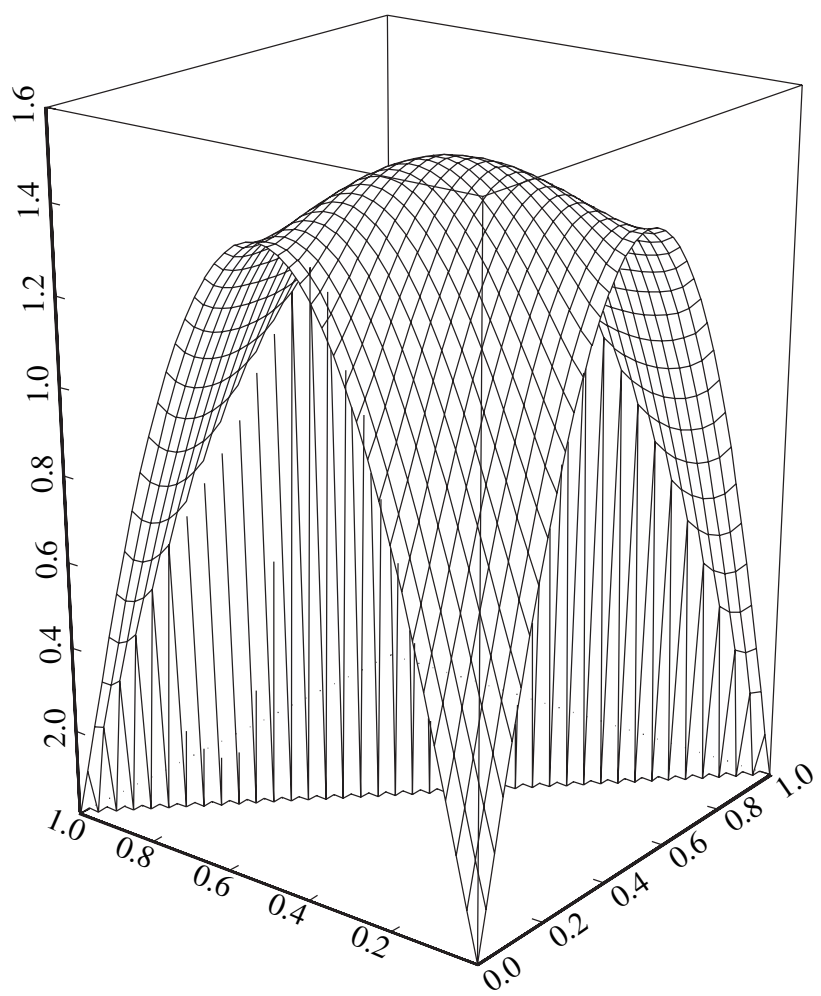

Fig. 4. Discrete Polarisation for $\alpha=0.5$

$\alpha=4 / 5$. As we showed before, this is actually an index of the family of fractionalisation measures. Alesina et al. (2003) and Collier and Hoeffler (2004) construct three indices of polarisation for three values of $\alpha\left(0,0.8\right.$ and 1.6) ${ }^{22}$ Obviously, the value 0 corresponds exactly to the traditional index of fractionalisation while the index with $\alpha=0.8$ belongs to the same family. Finally, the index of discrete polarisation with $\alpha=1.6$, admissible for the class of $P$ measures, is not appropriate for discrete polarisation. As we have shown before the only measure of discrete polarisation (with information about proportions but not distances across groups) that satisfies the above mentioned properties of polarisation is the one that sets $\alpha=1$, which is the RQ index.

\section{Discrete Ethnic Polarisation and Genocides}

Since World War II nearly 50 genocides and political mass murders have taken place. These episodes have killed at least 12 million combatants and as many as 22 million

\footnotetext{
22 Alesina et al. (2003) argue that 'Esteban and Ray, 1994 do not point to which values was "better" to capture polarisation - all values of $\alpha$ in the specified range satisfy the properties that the class of polarisation measures should satisfy. There is therefore no a priori reason to prefer one value over the other' (p.178, footnote 21).
}

(C) The Author(s). Journal compilation (C) Royal Economic Society 2008 


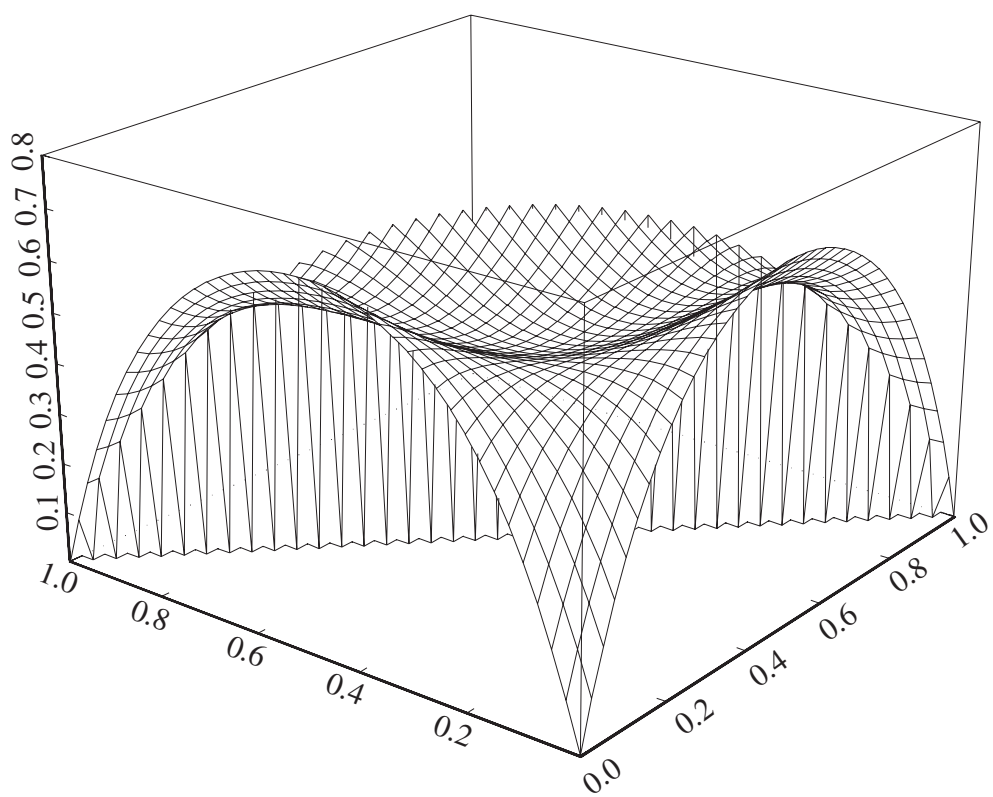

Fig. 5. Discrete Polarisation for $\alpha=1.5$
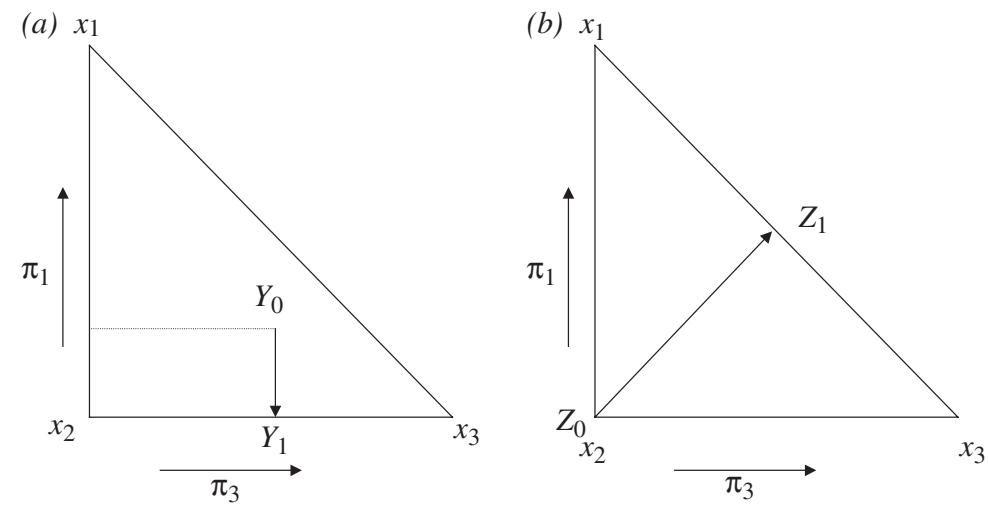

Fig. 6. Properties 1 and 2

non-combatants. These are more than all the victims of internal and international wars since $1945 .^{23}$ The human, social and economic consequences of genocides are extreme. The loss of human capital and trust among social groups, as well as the economic disruption, brings countries to an economic collapse after a genocide. Since early international intervention is crucial to avoid genocide, the study of the main

23 See the State Failure Task Force.

(C) The Author(s). Journal compilation (c) Royal Economic Society 2008 


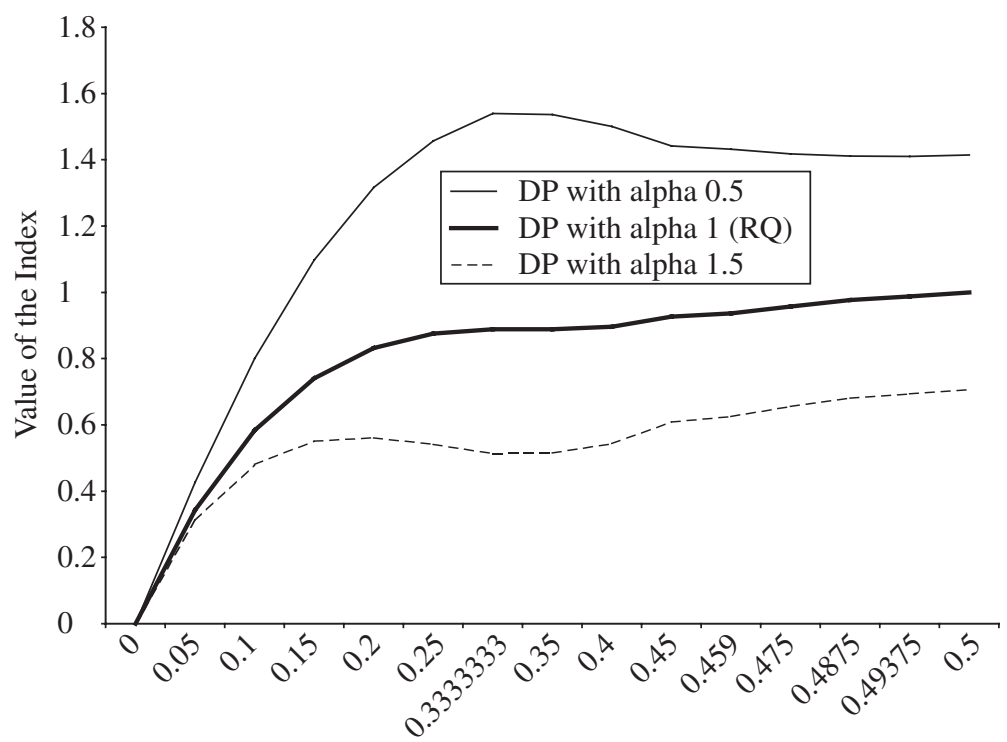

Size of the Transfer

Fig. 7. Value of the Index of Discrete Polarisation as a Function of the Parameter $\alpha$ and the Size of the Transfer

determinants of these episodes of social violence is an increasingly important issue in development economics. The crime of genocide is define in international law by the United Nations Genocide Convention (in force since January of 1951). Article II states that in the present Convention, genocide means any of the following acts committed with intent to destroy, in whole or in part, a national, ethnical, racial or religious groups, as such: (a) Killing members of the group, (b) Causing serious bodily or mental harm to members of the group; (c) Deliberately inflicting on the group conditions of life calculated to bring about its physical destruction in whole or in part; (d) Imposing measures intended to prevent births within the group; (e) Forcibly transferring children of the group to another group.'

Harff (2003) proposes an operational definition of genocide/politicide based on the previous legal definition but avoiding several of its limitations, in order to construct a dataset for empirical analysis. Harff (2003) defines genocide and politicide as events that involve the promotion, execution, and/or implied consent of sustained policies by governing elites or their agents - or in the case of civil war, either of the contending authorities - that result in the deaths of a substantial portion of a communal group or politicised non-communal group. In genocides, the victimised groups are defined primarily in terms of their communal (ethnolinguistic, religious) characteristics. In politicides, by contrast, groups are defined primarily in terms of their political opposition to the regime and dominant groups. Genocides and politicides are different to state repression and terror. In cases of state terror authorities arrest, persecute or execute a few members in ways designed to terrorise the majority of the group into passivity or acquiescence.

(C) The Author(s). Journal compilation (C) Royal Economic Society 2008 
In the case of genocide, authorities physically exterminate enough (not necessarily all) members of a target group so that it can no longer pose any conceivable threat to their rule or interests. Because genocide frequently involves the confrontation of ethnic, religious or nationalistic groups, we think it is an especially important case for the study of the relationship between conflict and alternative measures of ethnic diversity.

The literature that analyses the determinants of genocides is scarce. Recently, Harff (2003) constructed a dataset on genocides and politicides, as the principal investigator of the State Failure Task Force (genocide/politicide project) and tested a structural model of the antecedents of genocide and politicide. Harff (2003) identifies six causal factors and tests, in particular, the hypothesis that the greater the ethnic and religious diversity, the greater the likelihood that communal identity will lead to mobilisation and, if conflict is protracted, prompt elite decisions to eliminate the group basis of actual or potential challenges'. However, she finds no empirical evidence to support this hypothesis. The variables used to capture potential conflict were measures of diversity (ethnic fractionalisation). For this reason, and in line with most of the literature on the determinants of civil wars, Harff (2003) concludes that the effect of ethnic diversity on genocides is not statistically relevant. Fearon and Laitin (2003) and Collier and Hoeffler (2004) find that ethnic fractionalisation has no effect on the likelihood of the onset of a civil war. Easterly et al. (2006) analyse the determinant of mass killing which, they clarify, should not be confused with genocides. They find that mass killing is related with the square of ethnic fractionalisation. This suggests that polarisation of a society into two large groups would be the most dangerous situation even in the case of mass killing.

Theoretical models suggest that the risk of conflict is high when society is divided into two large groups of similar size. Moreover, Horowitz (1985) argues that the relationship between ethnic diversity and violence is not monotonic: there is less violence in highly homogeneous and highly heterogeneous societies, and more conflicts in societies where a large ethnic minority faces an ethnic majority. If this is so then an index of polarisation should capture the likelihood of genocides better than an index of fractionalisation.

Caselli and Coleman (2006) have recently proposed a theory of ethnic conflict where they argue that coalitions formed along ethnic lines compete for the economy's resources. Ethnicity enforces coalition membership. They claim, at least in the initial working paper version of the paper, that ethnic dominance could be an important factor in conflicts. The empirical results reported by Collier (2001) seems to indicate that a good operational definition of dominance implies a group that represents between $45 \%$ and $90 \%$ of the population. However, Collier and Hoeffler (2004) find that dominance, defined as mentioned above, has only a weak positive effect on the onset of civil wars. Ethnic dominance, or the existence of a large ethnic group, is related to ethnic polarisation although it does not capture some subtle aspects. Dominance implies the existence of a large group. A high degree of polarisation captures the idea of a large majority versus a large minority. Therefore, dominance is, in general, a necessary condition for a high degree of polarisation but it is not sufficient. 


\subsection{Data and Basic Specification}

In this Section we present the estimation of a logit model for the incidence of genocides as a function of ethnic and religious heterogeneity. The sample includes 138 countries during 1960-99. We divide the sample into five-year periods. The endogenous variable is the incidence of a genocide. The source is the State Failure Project dataset. ${ }^{24}$ We analyse whether genocides and the different, intense-type of civil wars, have the same ethnic roots, in terms of polarisation versus fractionalisation.

The explanatory variables follow the basic specifications of the civil wars' literature. ${ }^{25}$ Many of the determinants of civil wars were thought of as causes of conflict and, therefore, may also be important in the explanation of genocides. In general, the recent empirical literature emphasises the role of economic and geographical determinants of conflict. Fearon and Laitin (2003) argue that income per capita is a proxy for a 'state's overall financial, administrative, police and military capabilities'. Once a government is weak rebels can expect a higher probability of success. In addition, Collier and Hoeffler (2004) point out that a low level of income per capita reduces the opportunity cost of engaging in conflict.

The size of the population is another usual suspect in the explanation of conflict. Collier and Hoeffler (2004) consider that the size of the population is an additional proxy for the benefits of a rebellion since it measures potential labour income taxation. Fearon and Laitin (2003) indicate that a large population implies difficulties in controlling what goes on at the local level and increases the number of potential rebels that can be recruited by the insurgents. Similar arguments apply to genocides, which usually are perpetrated by rebel groups that have been recruited on the basis of ethnic identity.

Mountains are another dimension of opportunity since this terrain could provide a safe haven for rebels. Long distances from the centre of the state's power also favours the incidence of conflict, specially if there is a natural frontier between them, like a sea or other countries. Collier and Hoeffler (2004) point out that the existence of natural resources provides an opportunity for rebellion since these resources can be used to finance the war and increase the payoff if victory is achieved.

We emphasise the role of ethnic divisions. Our hypothesis is that ethnic polarisation will play a more important role in the explanation of genocides than in civil wars. We also use the concept of ethnic dominance as characterised by Collier (2001). There are three main sources of ethnolinguistic groups across countries: the World Christian Encyclopedia (Barret, 1982), the Encyclopedia Britannica and the Atlas Narodov Mira (1964). The most accurate description of ethnic diversity is the one in the WCE. We follow Vanhaven (1999) in taking only the most important ethnic divisions into account. Vanhaven (1999) uses a measure of genetic distance to separate different degrees of ethnic cleavage. The proxy for genetic distance is 'the period of time that two or more compared groups have been separated from each other, in the sense that intergroup marriage has been very rare. The longer the period of endogamous separation, the more groups have had time to differentiate.' This criterion is reasonable since we are using discrete distances and, therefore, have to determine the identity of

${ }^{24}$ See Appendix A2 for a precise definition.

25 See, for instance, Montalvo and Reynal-Querol (2005a,b), Fearon and Laitin (2003) and Collier and Hoeffler (2004).

(C) The Author(s). Journal compilation (C) Royal Economic Society 2008 
the relevant groups. Another source of data on ethnic diversity is the Encyclopedia Britannica, ${ }^{26}$ which uses the concept of geographical race. A third source of data on ethnolinguistic diversity is provided by the Atlas Narodov Mira (1964), the result of a large project of the Department of Geodesy and Cartography of the State Geological Committee of the old USSR.

Therefore the explanatory variables for the core specification of the incidence of genocide include the log of real GDP per capita in the initial year $(L G D P C)$, the $\log$ of the population at the beginning of the period (LPOP), primary exports (PRMEXP), mountains (MOUNTAINS), non-contiguous states (NONCONT) and the level of democracy (DEMOCRACY). ${ }^{27}$ Using this core specification we check the empirical performance of indices of ethnic fractionalisation (ETHFRAC), polarisation (ETHPOL) and dominance (ETHDOM). Table 1 presents the basic statistics for these variables, separating the sample by geographical regions and the aggregated results. Table 1 also includes the traditional ELF indicator of ethnolinguistic fractionalisation used by Mauro (1995). Ethnic polarisation and ethnic dominance are the highest in Latin America. However, it is interesting to notice that ethnic dominance has a much larger range than ethnic polarisation. It is also interesting to point out that while the average degree of polarisation of Sub-Saharan Africa is higher than the overall average, the opposite happens in the case of ethnic dominance. The highest degree of ethnic fractionalisation (either using the ETHFRAC variable or ELF) corresponds to SubSaharan Africa. This result is common to all the literature on ethnic fractionalisation starting with Easterly and Levine (1997).

Table 2 present the correlations across the alternative indices of ethnic heterogeneity. It also includes the correlations among the variables conditional on the degree of ethnic fractionalisation (above and below the median, percentile 25 and percentile $75)$. For the whole sample $(a)$ the correlation between dominance and any measure of fractionalisation is negative. Both measure of fractionalisation (ELF and ETHFRAC) have a very high degree of correlation (0.86). Finally, the index of polarisation has a

Table 1

Summary Statistics

\begin{tabular}{|c|c|c|c|c|c|c|c|c|c|c|}
\hline & \multicolumn{2}{|c|}{ All sample } & \multicolumn{2}{|c|}{$\begin{array}{c}\text { Sub-Saharan } \\
\text { Africa }\end{array}$} & \multicolumn{2}{|c|}{ Latin America } & \multicolumn{2}{|c|}{ Asia } & \multicolumn{2}{|c|}{ OECD } \\
\hline & Mean & Std. & Mean & Std. & Mean & Std. & Mean & Std. & Mean & Std. \\
\hline$L G D P C$ & 7.72 & 1.05 & 6.76 & 0.62 & 7.94 & 0.60 & 7.82 & 0.72 & 9.07 & 0.51 \\
\hline$\angle P O P$ & 15.39 & 1.94 & 15.15 & 1.42 & 14.69 & 1.96 & 14.95 & 2.45 & 16.09 & 1.83 \\
\hline PRIMEXP & 0.16 & 0.18 & 0.17 & 0.14 & 0.20 & 0.25 & 0.18 & 0.16 & 0.08 & 0.06 \\
\hline MOUNT & 15.19 & 20.04 & 12.73 & 21.72 & 18.19 & 17.89 & 10.31 & 14.30 & 17.05 & 20.67 \\
\hline NONCONT & 0.15 & 0.35 & 0.02 & 0.15 & 0.03 & 0.18 & 0.43 & 0.49 & 0.45 & 0.49 \\
\hline$D E M O C$ & 0.45 & 0.49 & 0.20 & 0.40 & 0.58 & 0.49 & 0.50 & 0.50 & 0.96 & 0.20 \\
\hline ETHPOL & 0.51 & 0.24 & 0.53 & 0.19 & 0.64 & 0.20 & 0.45 & 0.27 & 0.35 & 0.24 \\
\hline ETHFRAC & 0.44 & 0.27 & 0.63 & 0.26 & 0.44 & 0.19 & 0.35 & 0.27 & 0.23 & 0.20 \\
\hline ETHDOM & 0.52 & 0.49 & 0.39 & 0.48 & 0.75 & 0.42 & 0.43 & 0.49 & 0.41 & 0.49 \\
\hline$E L F$ & 0.41 & 0.29 & 0.65 & 0.24 & 0.26 & 0.21 & 0.46 & 0.28 & 0.21 & 0.20 \\
\hline
\end{tabular}

26 This is the basic source of data on ethnic heterogeneity of Alesina et al. (2003).

27 Appendix A3 describes the source of each of these variables.

(C) The Author(s). Journal compilation (c) Royal Economic Society 2008 
Table 2

Correlation Across Ethnic Indicators

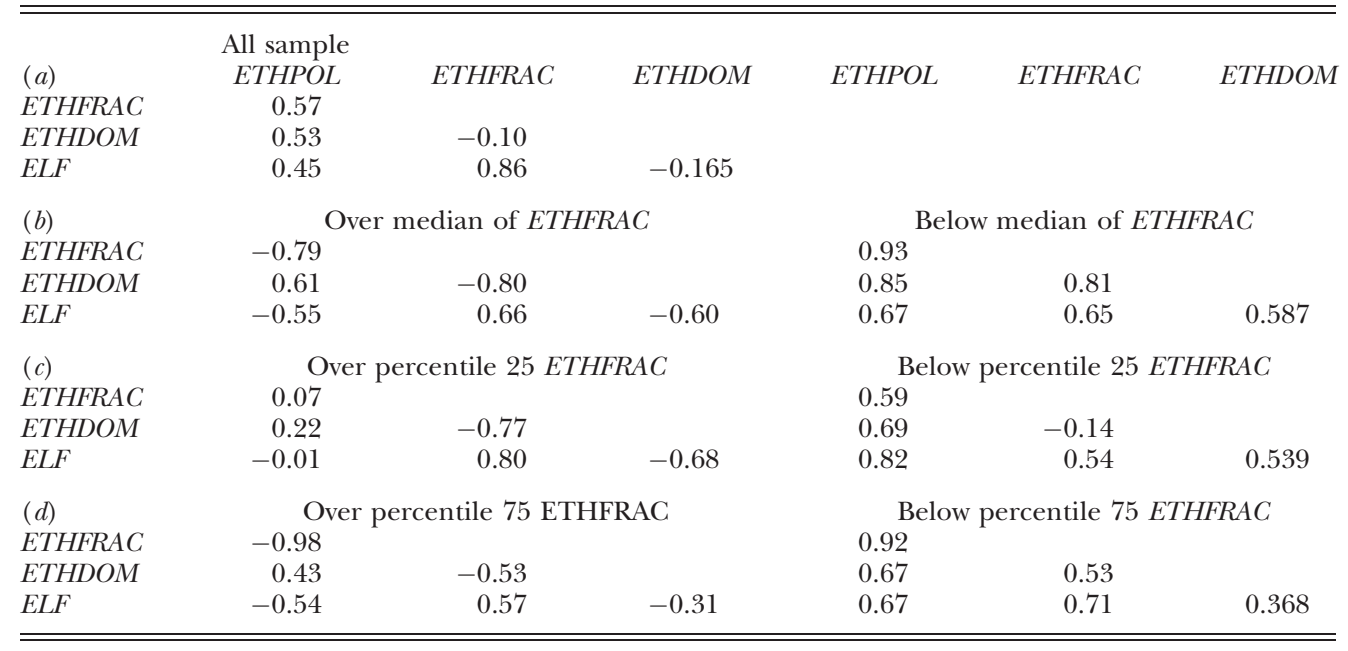

positive correlation with both, the indices of fractionalisation and the index of dominance.

Panels $(b)-(d)$ show the correlations conditional on different levels of ethnic fractionalisation. Several interesting facts are embedded in the results of those panels. First, the correlation between polarisation and fractionalisation is negative for countries over the median of the degree of fractionalisation and it is even more negative the higher is the percentile that defines the high level group. These results are not a surprise given the properties of discrete polarisation that we discuss in the theoretical part of the article. The correlation between polarisation and dominance as a function of the degree (high or low) of fractionalisation, is not monotonic: it is small for the countries over percentile 25 but the highest degree corresponds to countries over the median and not to the sample of countries over percentile 75 .

\subsection{Ethnic Heterogeneity and the Incidence of Genocides}

Table 3 reports the results of the estimation of the basic specification obtained using ethnic fractionalisation and ethnic polarisation measures. ${ }^{28}$ Column 1 shows that ethnic fractionalisation has no effect on genocides, confirming results from previous research. This indicates that highly fragmented societies have no higher risk of suffering a genocide than homogeneous societies. However, this does not mean that ethnicity does not matter for explaining genocides. If we substitute the index of ethnic fractionalisation by the index of ethnic polarisation we find a positive and statistically significant effect on the incidence of genocide, which is robust to the inclusion of the other typical controls on the core specification. Column 2 shows this result. Moreover, when including both measures together (column 3), we find that ethnic fractionalisation has no effect while ethnic

\footnotetext{
28 The Tables show the test statistics calculated using the corrected (clustered) standard deviation of the estimators.

(C) The Author(s). Journal compilation (C) Royal Economic Society 2008
} 
Table 3

Logit Regressions for the Incidence of Genocides (Including Politicides)

\begin{tabular}{lcccccc}
\hline \hline & $(1)$ & $(2)$ & $(3)$ & $(4)$ & $(5)$ & $(6)$ \\
\hline Constant & -7.13 & -8.17 & -7.76 & -7.86 & -9.21 & -9.88 \\
& $(-2.72)$ & $(-2.94)$ & $(-2.73)$ & $(-2.58)$ & $(-3.00)$ & $(-3.25)$ \\
LGDPC & -0.41 & -0.45 & -0.57 & -0.43 & -0.40 & -0.48 \\
& $(-1.28)$ & $(-1.47)$ & $(-1.83)$ & $(-1.52)$ & $(-1.51)$ & $(-1.71)$ \\
LPOP & 0.42 & 0.43 & 0.47 & 0.46 & 0.46 & 0.55 \\
& $(4.31)$ & $(4.14)$ & $(4.85)$ & $(3.17)$ & $(3.58)$ & $(3.91)$ \\
PRIMEXP & 2.11 & 1.93 & 2.23 & 2.19 & 1.86 & 2.27 \\
& $(1.32)$ & $(1.25)$ & $(1.44)$ & $(1.23)$ & $(1.09)$ & $(1.31)$ \\
MOUNTAINS & 0.01 & 0.01 & 0.01 & 0.01 & 0.01 & 0.008 \\
& $(1.42)$ & $(0.78)$ & $(0.59)$ & $(1.41)$ & $(0.82)$ & $(0.63)$ \\
NONCONT & 0.73 & 0.91 & 0.99 & 0.66 & 0.85 & 1.018 \\
& $(0.92)$ & $(1.21)$ & $(1.32)$ & $(0.65)$ & $(0.89)$ & $(1.09)$ \\
DEMOCRACY & -1.07 & -1.09 & -1.08 & -1.07 & -1.10 & -1.10 \\
& $(-1.71)$ & $(-1.79)$ & $(-1.79)$ & $(-1.72)$ & $(-1.78)$ & $(-1.79)$ \\
ETHFRAC & 0.28 & & -0.96 & 0.12 & & -1.37 \\
& $(0.43)$ & & $(-0.99)$ & $(0.16)$ & & $(-1.22)$ \\
ETHPOL & & 2.32 & 2.75 & & 2.25 & 2.90 \\
& & $(2.17)$ & $(2.35)$ & & $(1.98)$ & $(2.25)$ \\
Regional dummies & No & No & No & Yes & Yes & Yes \\
Pseudo R ${ }^{2}$ & 0.137 & 0.15 & 0.16 & 0.14 & 0.16 & 0.164 \\
N & 846 & 846 & 846 & 846 & 846 & 846 \\
\hline \hline
\end{tabular}

Cluster-corrected standard errors are used to calculate the z-statistics included in parenthesis.

polarisation has a positive and significant effect on the incidence of genocides/politicides. The results are mostly unchanged if we include regional dummies (columns 4-7). Therefore, ethnic heterogeneity, measured as ethnic polarisation, is important for the explanation of the likelihood of genocides. Moving from social homogeneity (one group or polarisation equal to 0 ) to the highest degree of polarisation (two groups of equal size or the index equal to 1 ) increases the probability of a genocide by 7 percentage points. If the polarisation index increases one standard deviation (0.24) from the average $(0.51)$ the probability of genocide increases 1.7 percentage points.

The State Failure Project (SFP) includes genocides and politicides together. In many situations genocides and politicides are part of the same process, mainly because ethnic divisions are reflected in political parties. In order to separate the cases that are purely politicides, meaning that the main divisions are not ethnic, religious, racial or nationalistic, we use the information in Harff (2003). Among all the genocides/ politicides in our sample, the SFP lists two cases as politicides: Chile and El Salvador. We test the robustness of our results excluding these two countries. Columns 1 to 3 of Table 4 corroborate the findings of Table 3 . Once the two pure politicides are excluded the coefficient on ethnic polarisation increases. The results are qualitative identical if we add the regional dummies as regressors.

The majority of the genocides and politicides coded by SFP took place during the course of an ethnic civil war, as defined by SFP. Very few episodes are consider genocides/politicides with no civil war. We test the sensitivity of the results to the exclusion of the genocides/politicides that were not considered a civil war. Table 5 shows that ethnic fractionalisation has no significant effect on genocides associated with civil wars. However, if instead of fractionalisation we include ethnic polarisation, 
Table 4

Logit Regressions on the Incidence of Genocides*

\begin{tabular}{|c|c|c|c|c|c|c|}
\hline & (1) & (2) & (3) & (4) & (5) & (6) \\
\hline \multirow[t]{2}{*}{ Constant } & -7.22 & -8.41 & -7.98 & -7.76 & -9.82 & -10.30 \\
\hline & $(-2.53)$ & $(-2.71)$ & $(-2.51)$ & $(-2.42)$ & $(-3.04)$ & $(-3.22)$ \\
\hline \multirow[t]{2}{*}{$L G D P C$} & -0.44 & -0.50 & -0.61 & -0.41 & -0.38 & -0.46 \\
\hline & $(-1.25)$ & $(-1.49)$ & $(-1.78)$ & $(-1.37)$ & $(-1.37)$ & $(-1.55)$ \\
\hline \multirow[t]{2}{*}{$\angle P O P$} & 0.43 & 0.46 & 0.49 & 0.45 & 0.48 & 0.56 \\
\hline & $(4.32)$ & $(4.00)$ & $(4.68)$ & $(3.07)$ & $(3.55)$ & $(3.90)$ \\
\hline \multirow[t]{2}{*}{ PRIMEXP } & 1.98 & 1.83 & 2.10 & 1.94 & 1.69 & 2.02 \\
\hline & (1.19) & $(1.15)$ & (1.31) & $(1.07)$ & $(0.97)$ & $(1.15)$ \\
\hline \multirow[t]{2}{*}{ MOUNTAINS } & 0.01 & 0.006 & 0.003 & 0.01 & 0.01 & 0.005 \\
\hline & (1.12) & $(0.41)$ & $(0.26)$ & (1.18) & $(0.53)$ & $(0.37)$ \\
\hline \multirow[t]{2}{*}{ NONCONT } & 0.91 & 1.11 & 1.19 & 0.79 & 1.04 & 1.18 \\
\hline & (1.13) & (1.48) & $(1.57)$ & $(0.74)$ & $(1.05)$ & (1.22) \\
\hline \multirow[t]{2}{*}{ DEMOCRACY } & -1.35 & -1.37 & -1.35 & -1.30 & -1.33 & -1.34 \\
\hline & $(-1.94)$ & $(-2.02)$ & $(-2.03)$ & $(-1.83)$ & $(-1.89)$ & $(-1.91)$ \\
\hline \multirow[t]{2}{*}{ ETHFRAC } & 0.39 & & -0.86 & 0.33 & & -1.22 \\
\hline & $(0.57)$ & & $(-0.83)$ & $(0.42)$ & & $(-1.03)$ \\
\hline \multirow[t]{2}{*}{ ETHPOL } & & 2.64 & 2.99 & & 2.77 & 3.29 \\
\hline & & (2.19) & $(2.34)$ & & $(2.28)$ & $(2.47)$ \\
\hline Regional dummies & No & No & No & Yes & Yes & Yes \\
\hline Pseudo $\mathrm{R}^{2}$ & 0.156 & 0.181 & 0.183 & 0.1575 & 0.1831 & 0.1869 \\
\hline$N$ & 846 & 846 & 846 & 846 & 846 & 846 \\
\hline
\end{tabular}

*Excluding Chile and El Salvador

Cluster-corrected standard errors are used to calculate the z-statistics included in parenthesis.

Table 5

Logit Regressions of the Incidence of Genocides with Civil Wars

\begin{tabular}{|c|c|c|c|c|c|c|}
\hline & (1) & (2) & (3) & (4) & (5) & (6) \\
\hline Constant & $\begin{array}{c}-3.22 \\
(-0.93)\end{array}$ & $\begin{array}{c}-4.65 \\
(-1.12)\end{array}$ & $\begin{array}{c}-4.24 \\
(-1.04)\end{array}$ & $\begin{array}{c}-4.37 \\
(-1.34)\end{array}$ & $\begin{array}{c}-7.28 \\
(-1.94)\end{array}$ & $\begin{array}{c}-7.65 \\
(-2.07)\end{array}$ \\
\hline$L G D P C$ & $\begin{array}{c}-0.64 \\
(-1.56)\end{array}$ & $\begin{array}{c}-0.72 \\
(-1.77)\end{array}$ & $\begin{array}{l}-0.81 \\
(-2.15)\end{array}$ & $\begin{array}{c}-0.55 \\
(-1.76)\end{array}$ & $\begin{array}{l}-0.50 \\
(-1.65)\end{array}$ & $\begin{array}{c}-0.57 \\
(-1.86)\end{array}$ \\
\hline$\angle P O P$ & $\begin{array}{c}0.25 \\
(1.77)\end{array}$ & $\begin{array}{c}0.29 \\
(1.74)\end{array}$ & $\begin{array}{c}0.33 \\
(1.89)\end{array}$ & $\begin{array}{c}0.28 \\
(1.63)\end{array}$ & $\begin{array}{c}0.33 \\
(1.88)\end{array}$ & $\begin{array}{c}0.41 \\
(2.19)\end{array}$ \\
\hline PRIMEXP & $\begin{array}{c}2.15 \\
(1.39)\end{array}$ & $\begin{array}{c}1.92 \\
(1.24)\end{array}$ & $\begin{array}{c}2.11 \\
(1.36)\end{array}$ & $\begin{array}{c}2.03 \\
(1.23)\end{array}$ & $\begin{array}{c}1.70 \\
(1.02)\end{array}$ & $\begin{array}{c}1.95 \\
(1.16)\end{array}$ \\
\hline MOUNTAINS & $\begin{array}{c}0.01 \\
(0.97)\end{array}$ & $\begin{array}{c}0.005 \\
(0.30)\end{array}$ & $\begin{array}{c}0.00 \\
(0.16)\end{array}$ & $\begin{array}{c}0.01 \\
(1.13)\end{array}$ & $\begin{array}{c}0.008 \\
(0.51)\end{array}$ & $\begin{array}{c}0.004 \\
(0.33)\end{array}$ \\
\hline NONCONT & $\begin{array}{c}1.50 \\
(1.79)\end{array}$ & $\begin{array}{l}1.70 \\
(2.13)\end{array}$ & $\begin{array}{c}1.76 \\
(2.26)\end{array}$ & $\begin{array}{c}1.33 \\
(1.26)\end{array}$ & $\begin{array}{c}1.62 \\
(1.64)\end{array}$ & $\begin{array}{c}1.75 \\
(1.82)\end{array}$ \\
\hline DEMOCRACY & $\begin{array}{l}-1.25 \\
(-1.62)\end{array}$ & $\begin{array}{c}-1.30 \\
(-1.69)\end{array}$ & $\begin{array}{c}-1.30 \\
(-1.69)\end{array}$ & $\begin{array}{c}-1.18 \\
(-1.51)\end{array}$ & $\begin{array}{l}-1.24 \\
(-1.55)\end{array}$ & $\begin{array}{l}-1.26 \\
(-1.56)\end{array}$ \\
\hline ETHFRAC & $\begin{array}{c}0.51 \\
(0.71)\end{array}$ & & $\begin{array}{c}-0.77 \\
(-0.71)\end{array}$ & $\begin{array}{c}0.42 \\
(0.57)\end{array}$ & & $\begin{array}{c}-1.21 \\
(-1.05)\end{array}$ \\
\hline ETHPOL & & $\begin{array}{c}2.94 \\
(2.15)\end{array}$ & $\begin{array}{c}3.22 \\
(2.28)\end{array}$ & & $\begin{array}{c}3.21 \\
(2.41)\end{array}$ & $\begin{array}{c}3.67 \\
(2.55)\end{array}$ \\
\hline Regional dummies & No & No & No & Yes & Yes & Yes \\
\hline Pseudo $\mathrm{R}^{2}$ & 0.153 & 0.182 & 0.183 & 0.1560 & 0.188 & 0.191 \\
\hline$N$ & 846 & 846 & 846 & 846 & 846 & 846 \\
\hline
\end{tabular}

Cluster-corrected standard errors are used to calculate the z-statistics included in parenthesis.

(C) The Author(s). Journal compilation (C) Royal Economic Society 2008 


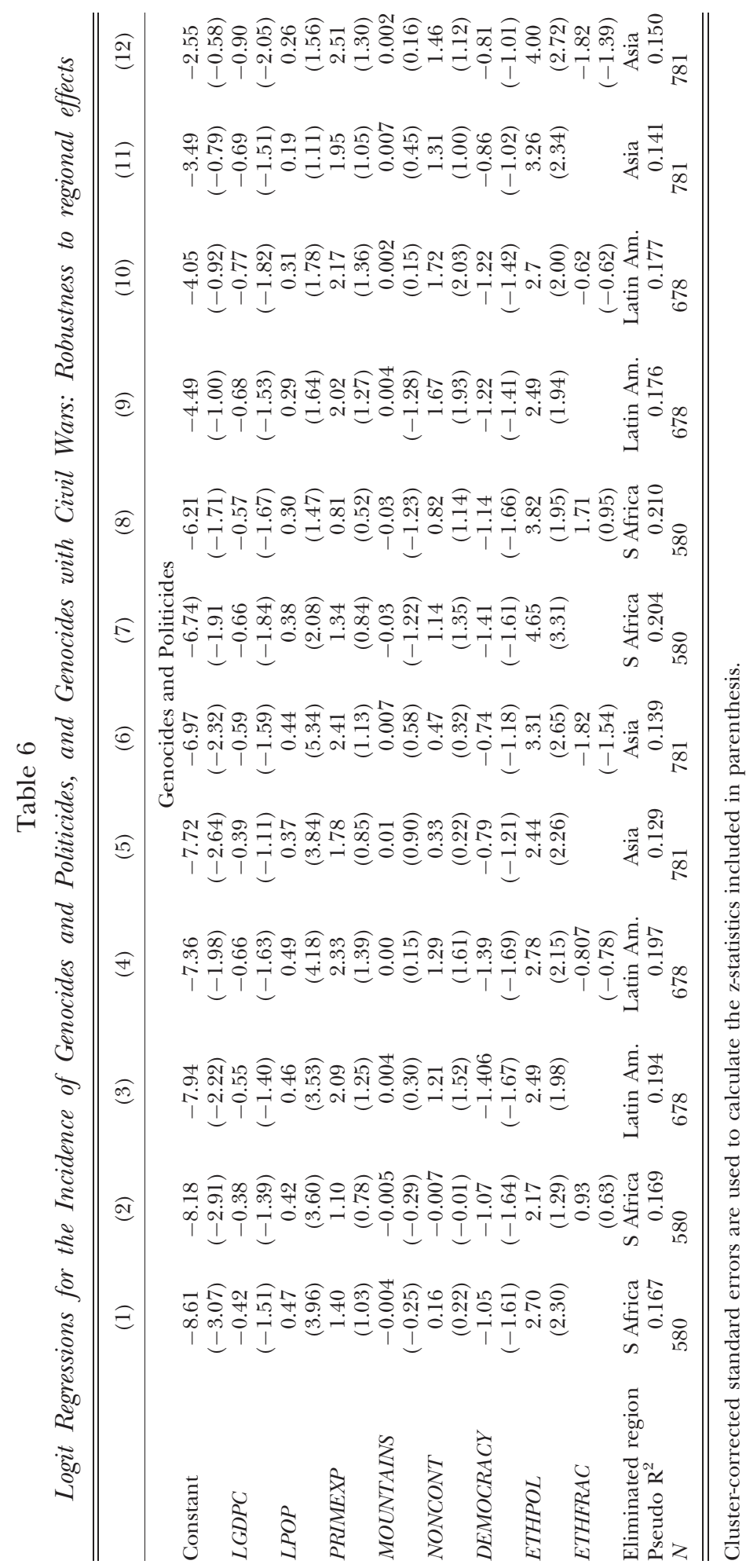


this variable has a positive and significant effect on the incidence of civil war (column 2). If we include both measures (column 3), we find that only polarisation has a statistically significant effect on genocides. The results are unchanged if we include the regional dummies in the regression.

We also analyse whether the results presented previously are robust to the exclusion of some geographical regions. Table 6 considers the estimation of the basic specification eliminating, in sequential steps, Sub-Saharan African countries, Latin American countries and the countries of Asia. The results indicate that ethnic polarisation has a positive and significant effect on genocide, even in the presence of ethnic fractionalisation and even when the genocide is part of an ongoing civil war. The statistical significance of ethnic polarisation is robust to all these different subsamples.

Table 7 includes the ethnic dominance variable in the basic regression. Column 1 shows that ethnic dominance is not statistically significant in explaining the incidence of genocides at the usual level of significance. Column 2 shows that when dominance and polarisation are included together then none of them is statistically significant. However, there are several variables that are not significant and some authors do not consider the proportion of mountains and non-continguous areas and the size of primary exports in the basic specification of the incidence of civil wars. Since these variables are never statistically significant we run the regressions without them. In those specifications, ethnic polarisation is statistically significant (at least in some specification) while ethnic dominance is not significant.

Table 7

Logit Regressions for the Incidence of Genocides

\begin{tabular}{|c|c|c|c|c|c|c|}
\hline & (1) & (2) & (3) & (4) & (5) & (6) \\
\hline & \multicolumn{2}{|c|}{$\begin{array}{l}\text { Genocides and } \\
\text { Politicides }\end{array}$} & \multicolumn{2}{|c|}{ Genocides* } & \multicolumn{2}{|c|}{$\begin{array}{c}\text { Genocides and Civil } \\
\text { Wars }\end{array}$} \\
\hline Constant & $\begin{array}{c}-9.35 \\
(-2.92)\end{array}$ & $\begin{array}{c}-9.56 \\
(-3.08)\end{array}$ & $\begin{array}{l}-7.75 \\
(-2.57)\end{array}$ & $\begin{array}{l}-8.57 \\
(-2.74)\end{array}$ & $\begin{array}{c}-9.68 \\
(-2.93)\end{array}$ & $\begin{array}{c}-7.44 \\
(-1.96)\end{array}$ \\
\hline$L G D P C$ & $\begin{array}{c}-0.48 \\
(-1.80)\end{array}$ & $\begin{array}{l}-0.46 \\
(-1.68)\end{array}$ & $\begin{array}{l}-0.46 \\
(-1.60)\end{array}$ & $\begin{array}{l}-0.44 \\
(-1.49)\end{array}$ & $\begin{array}{c}-0.39 \\
(-1.28)\end{array}$ & $\begin{array}{c}-0.49 \\
(-1.38)\end{array}$ \\
\hline$\angle P O P$ & $\begin{array}{c}0.53 \\
(3.69)\end{array}$ & $\begin{array}{c}0.50 \\
(3.61)\end{array}$ & $\begin{array}{c}0.48 \\
(3.65)\end{array}$ & $\begin{array}{c}0.47 \\
(3.67)\end{array}$ & $\begin{array}{c}0.50 \\
(3.70)\end{array}$ & $\begin{array}{c}0.38 \\
(2.16)\end{array}$ \\
\hline PRIMEXP & $\begin{array}{c}2.81 \\
(1.74)\end{array}$ & $\begin{array}{c}2.28 \\
(1.37)\end{array}$ & & & & \\
\hline MOUNTAINS & $\begin{array}{c}0.01 \\
(1.25)\end{array}$ & $\begin{array}{c}0.01 \\
(0.93)\end{array}$ & & & & \\
\hline NONCONT & $\begin{array}{l}1.05 \\
(1.10)\end{array}$ & $\begin{array}{l}1.05 \\
(1.11)\end{array}$ & & & & \\
\hline DEMOCRACY & $\begin{array}{c}-1.12 \\
(-1.77)\end{array}$ & $\begin{array}{c}-1.13 \\
(-1.81)\end{array}$ & $\begin{array}{l}-0.90 \\
(-1.74)\end{array}$ & $\begin{array}{c}-0.90 \\
(-1.76)\end{array}$ & $\begin{array}{c}-1.06 \\
(-1.86)\end{array}$ & $\begin{array}{c}-0.83 \\
(-1.28)\end{array}$ \\
\hline ETHDOM & $\begin{array}{c}0.93 \\
(1.83)\end{array}$ & $\begin{array}{c}0.68 \\
(1.20)\end{array}$ & $\begin{array}{c}0.70 \\
(1.39)\end{array}$ & $\begin{array}{c}0.36 \\
(0.59)\end{array}$ & $\begin{array}{c}0.38 \\
(0.58)\end{array}$ & $\begin{array}{c}0.21 \\
(0.32)\end{array}$ \\
\hline ETHPOL & & $\begin{array}{l}1.58 \\
(1.33)\end{array}$ & & $\begin{array}{l}1.95 \\
(1.70)\end{array}$ & $\begin{array}{l}2.29 \\
(1.81)\end{array}$ & $\begin{array}{c}2.77 \\
(2.06)\end{array}$ \\
\hline Regional dummies & Yes & Yes & Yes & Yes & Yes & Yes \\
\hline Pseudo $\mathrm{R}^{2}$ & 0.158 & 0.167 & 0.132 & 0.147 & 0.170 & 0.158 \\
\hline$N$ & 846 & 846 & 859 & 859 & 859 & 859 \\
\hline
\end{tabular}

*Excluding El Salvador and Chile

Cluster-corrected standard errors are used to calculate the z-statistics included between parenthesis.

(C) The Author(s). Journal compilation (C) Royal Economic Society 2008 


\subsection{Ethnic Heterogeneity and High-death, Intermediate and Minor Civil Wars}

Genocide and politicide are extreme forms of civil conflicts. Given our previous discussion, it seems reasonable to expect that the effect of ethnic polarisation on the probability of a conflict is reduced the less intense is the conflict. In order to test this hypothesis, we need a classification of civil wars depending on their intensity. There is no doubt that genocide and politicide are the most violent conflicts. Civil wars can be classified depending of their intensity in terms of the number of deaths. The dataset on civil wars of Uppsala/PRIO (Peace Research Institute of Oslo) is the most widely used data on civil wars. Uppsala/PRIO defines an armed conflict as a contested incompatibility that concerns government and/or territory where the use of armed force between two parties, of which at least one is the government of a state, results in at least 25 battle-related deaths. We consider only civil war conflict (type 3 and 4 from Uppsala/PRIO classification), excluding interstate war. Uppsala/PRIO distinguish three types of conflicts depending on the number of deaths:

- Minor armed conflict: at least 25 battle-related deaths per year and fewer than 1,000 battle-related deaths during the course of the conflict.

- Intermediate Armed Conflict: At least 25 battle-related deaths per year and an accumulated total of at least 1,000 deaths but fewer than 1,000 per year.

- War: At least 1,000 battle-related deaths per year. ${ }^{29}$

These classifications allow us to distinguish three types of civil wars, from more to less intense, and to compare the effect of ethnic polarisation on genocides, high intensity civil wars, intermediate and minor civil wars. In column 1 and 2 of Table 8 we analyse the effect ethnic polarisation on the incidence of civil wars that involve more than 1,000 deaths a year. These results indicate that ethnic polarisation has a positive and significant effect on the incidence of highly intense civil wars, even in the presence of ethnic fractionalisation, which has no significant effect. ${ }^{30}$ Moving from an homogeneous country (polarisation $=0$ ) to a totally polarised county (polarisation $=1$ ) the probability of an extreme civil war increases by 17 percentage points (based on column 1). In Column 3 and 4, we estimate the determinants of intermediate civil war. The results indicate that polarisation is still an important determinant of this type of conflict: an increase of the index of polarisation from 0 to 1 increases the probability of a medium intensity war by 14 percentage points. Finally in columns 5 and 6 , the dependent variable is a dummy that has the value 1 if the country had a minor conflict during the period. In this case ethnic polarisation does not have a significant role in explaining the incidence of conflict.

As a final check of the robustness of the results, Table 9 contains the estimation of the specification excluding the variables that were not significant in any of the previous tables. Therefore, we exclude primary exports, mountains and non-contiguous territories. Following the previous strategy columns 1, 2 and 3 present the

\footnotetext{
${ }^{29}$ This definition is practically identical to Singer and Small (1994) in the Correlates of War Project (COW).

30 The regression of column 2 is a replication of Montalvo and Reynal-Querol $(2005 a)$. We include it here as a matter of comparison with genocides and low intensity civil war.

(C) The Author(s). Journal compilation (C) Royal Economic Society 2008
} 
Table 8

Logit Regressions for the Incidence of Major, Intermediate and Minor Civil Wars

\begin{tabular}{|c|c|c|c|c|c|c|}
\hline & (1) & (2) & (3) & (4) & (5) & (6) \\
\hline & Major & Major & Intermediate & Intermediate & Minor & Minor \\
\hline \multirow{2}{*}{ Constant } & -4.01 & -4.33 & -7.98 & -7.93 & -0.91 & -1.01 \\
\hline & $(-1.32)$ & $(-1.54)$ & $(-2.30)$ & $(-2.31)$ & $(-0.48)$ & $(-0.55)$ \\
\hline \multirow[t]{2}{*}{$L G D P C$} & -0.69 & -0.62 & -0.23 & -0.25 & -0.70 & -0.66 \\
\hline & $(-3.09)$ & $(-2.78)$ & $(-0.99)$ & $(-1.01)$ & $(-4.57)$ & $(-3.84)$ \\
\hline \multirow[t]{2}{*}{$L P O P$} & 0.33 & 0.30 & 0.40 & 0.40 & 0.21 & 0.20 \\
\hline & $(2.27)$ & $(1.94)$ & $(2.32)$ & $(2.18)$ & $(2.11)$ & $(1.79)$ \\
\hline \multirow[t]{2}{*}{ PRIMEXP } & 0.14 & -0.02 & -2.25 & -2.19 & 0.55 & 0.48 \\
\hline & $(0.09)$ & $(-0.01)$ & $(-0.89)$ & $(-0.86)$ & $(0.46)$ & $(0.38)$ \\
\hline \multirow[t]{2}{*}{ MOUNTAINS } & 0.00 & 0.005 & -0.00 & -0.002 & 0.003 & 0.00 \\
\hline & $(0.40)$ & $(0.54)$ & $(-0.22)$ & $(-0.24)$ & $(0.59)$ & $(0.65)$ \\
\hline \multirow[t]{2}{*}{ NONCONT } & 0.34 & 0.30 & 0.40 & 0.40 & 0.67 & 0.66 \\
\hline & $(0.55)$ & $(0.50)$ & $(0.57)$ & $(0.61)$ & $(1.51)$ & $(1.47)$ \\
\hline \multirow[t]{2}{*}{ DEMOCRACY } & 0.04 & 0.04 & 0.25 & 0.25 & 0.33 & 0.33 \\
\hline & $(0.09)$ & $(0.09)$ & $(0.55)$ & $(0.55)$ & $(1.12)$ & (1.12) \\
\hline \multirow[t]{2}{*}{ ETHFRAC } & & 0.57 & & -0.15 & & 0.23 \\
\hline & & $(0.52)$ & & $(-0.14)$ & & $(0.29)$ \\
\hline \multirow[t]{2}{*}{ ETHPOL } & 2.55 & 2.33 & 2.11 & 2.19 & 0.61 & 0.49 \\
\hline & $(2.74)$ & $(2.16)$ & $(2.75)$ & $(2.19)$ & $(1.02)$ & $(0.63)$ \\
\hline Pseudo $\mathrm{R}^{2}$ & 0.128 & 0.129 & 0.111 & 0.112 & 0.082 & 0.082 \\
\hline$N$ & 846 & 846 & 846 & 846 & 846 & 846 \\
\hline
\end{tabular}

Cluster-corrected standard errors are used to calculate the z-statistics included between parenthesis.

Table 9

Logit Regressions for the Incidence of Genocides: Robustness to a Reduced Set of Variables and Cross-section Analysis

\begin{tabular}{|c|c|c|c|c|c|c|}
\hline & (1) & (2) & (3) & (4) & (5) & (6) \\
\hline & \multicolumn{3}{|c|}{ Five year periods } & \multicolumn{3}{|c|}{ Cross section } \\
\hline & $\begin{array}{c}\text { Genocides } \\
\text { and } \\
\text { Politicides }\end{array}$ & Genocides* & $\begin{array}{c}\text { Genocides } \\
\text { and } \\
\text { Civil Wars }\end{array}$ & $\begin{array}{l}\text { Genocides } \\
\text { and } \\
\text { Politicides }\end{array}$ & Genocides* & $\begin{array}{c}\text { Genocides } \\
\text { and } \\
\text { Civil Wars }\end{array}$ \\
\hline Constant & $\begin{array}{c}-8.04 \\
(-2.53)\end{array}$ & $\begin{array}{c}-8.67 \\
(-2.53)\end{array}$ & $\begin{array}{c}-5.91 \\
(-1.42)\end{array}$ & $\begin{array}{c}-4.68 \\
(-1.22)\end{array}$ & $\begin{array}{c}-7.13 \\
(-1.59)\end{array}$ & $\begin{array}{c}-4.10 \\
(-0.88)\end{array}$ \\
\hline$L G D P C$ & $\begin{array}{c}-0.45 \\
(-1.49)\end{array}$ & $\begin{array}{c}-0.45 \\
(-1.36)\end{array}$ & $\begin{array}{c}-0.57 \\
(-1.50)\end{array}$ & $\begin{array}{c}-0.59 \\
(-1.45)\end{array}$ & $\begin{array}{c}-0.61 \\
(-1.38)\end{array}$ & $\begin{array}{c}-0.67 \\
(-1.45)\end{array}$ \\
\hline$\angle P O P$ & $\begin{array}{c}0.46 \\
(4.54)\end{array}$ & $\begin{array}{c}0.49 \\
(4.49)\end{array}$ & $\begin{array}{c}0.35 \\
(2.14)\end{array}$ & $\begin{array}{c}0.66 \\
(2.64)\end{array}$ & $\begin{array}{c}0.81 \\
(2.80)\end{array}$ & $\begin{array}{c}0.47 \\
(1.89)\end{array}$ \\
\hline DEMOCRACY & $\begin{array}{c}-0.89 \\
(-1.70)\end{array}$ & $\begin{array}{c}-1.09 \\
(-1.89)\end{array}$ & $\begin{array}{c}-0.86 \\
(-1.31)\end{array}$ & $\begin{array}{c}-0.69 \\
(-0.97)\end{array}$ & $\begin{array}{c}-0.92 \\
(-1.16)\end{array}$ & $\begin{array}{c}-0.25 \\
(-0.32)\end{array}$ \\
\hline ETHFRAC & $\begin{array}{c}-0.43 \\
(-0.38)\end{array}$ & $\begin{array}{c}-1.10 \\
(-0.09)\end{array}$ & $\begin{array}{c}0.23 \\
(0.17)\end{array}$ & $\begin{array}{c}-1.14 \\
(-0.64)\end{array}$ & $\begin{array}{c}-0.12 \\
(-0.06)\end{array}$ & $\begin{array}{c}0.75 \\
(0.37)\end{array}$ \\
\hline ETHPOL & $\begin{array}{c}2.51 \\
(2.32)\end{array}$ & $\begin{array}{c}2.51 \\
(2.23)\end{array}$ & $\begin{array}{c}2.53 \\
(2.03)\end{array}$ & $\begin{array}{c}3.87 \\
(2.16)\end{array}$ & $\begin{array}{c}4.60 \\
(2.16)\end{array}$ & $\begin{array}{c}4.23 \\
(1.95)\end{array}$ \\
\hline Pseudo $\mathrm{R}^{2}$ & 0.141 & 0.160 & 0.136 & 0.231 & 0.302 & 0.232 \\
\hline$N$ & 859 & 859 & 859 & 91 & 91 & 91 \\
\hline
\end{tabular}

*Excluding El Salvador and Chile

Cluster-corrected standard errors are used to calculate the z-statistics included between parenthesis.

(C) The Author(s). Journal compilation (C) Royal Economic Society 2008 
estimation for both genocides and politicides, only genocides and genocides that happened during a civil war, respectively. In all cases we confirm that ethnic polarisation is a statistically significant determinant of genocides. Finally, this result is robust to running the logit regressions in a cross section (column 4 to 6), where the dependent variable takes the value 1 if a country has suffered a genocide during the whole period (1960-99) and zero otherwise. The values of GDP per capita, population and democracy are measured at the beginning of the period (1960). The results show that ethnic polarisation has a significant and positive effect in explaining the incidence of genocides even if we consider only the cross section for the whole period.

\section{Conclusions}

The economic literature has recognised for some time that inequality and polarisation are two different concepts. As in the case of inequality, the measurement of polarisation was initially developed in the context of a continuous dimension, in particular income, which defined the 'closeness' of the characteristics of individuals and clusters. Esteban and Ray (1994) present the properties of a precise axiomatisation of a class of polarisation measures based on distances in the real line. However, in many important dimensions (like ethnicity or religion), there is no information on a continuous variable to measure distances across groups. In addition, if there was such a proxy for 'ethnic distances', that measure would be much more controversial than the identification of the list of ethnic groups. Finally, in many instances, and ethnicity is one of them, individuals are only interested in the dichotomous perception 'we versus they'. For these reasons we analyse the theoretical properties of a measure of polarisation based on classifications instead of continuous distances across groups in this article. We show that the range of parameter values suitable for this measure of discrete polarisation is different from the ones in the original polarisation measure of Esteban and Ray (1994). This is important since some recent papers have constructed measures of polarisation using data on groups, without information on distances, assuming that the range of suitable parameters of the original index can be directly applied to discrete polarisation.

The second part of the article presents an application of the index of discrete ethnic polarisation to the explanation of genocides. Most of the recent papers on the determinants of civil wars and genocides fail to find any significant effect for ethnic heterogeneity, measured as fractionalisation. However, Horowitz (1985) argues that the relationship between ethnic diversity and violence is not monotonic: there is less violence in highly homogeneous and highly heterogeneous societies, and more conflicts in societies where a large ethnic minority faces an ethnic majority. If this is so then an index of polarisation should capture better the likelihood of genocides than an index of fractionalisation. We argue that the use of ethnic fractionalisation instead of an index of polarisation is the main reason for the failure to find a significant effect of ethnic heterogeneity on the probability of genocides. The empirical results support this interpretation. 


\section{Appendix}

\section{A.1. Proofs}

Proof of Theorem 1

Proof of sufficiency: The general discrete polarisation index can be written as

$$
\begin{aligned}
D P(\alpha, k) & =k \sum_{i=1}^{n} \sum_{j \neq i} \pi_{i}^{1+\alpha} \pi_{j}=k \sum_{i=1}^{n} \pi_{i}^{1+\alpha}\left(1-\pi_{i}\right)=\sum_{i=1}^{n} k\left[\pi_{i}\left(\pi_{i}^{\alpha}-\pi_{i}^{1+\alpha}\right)\right] \\
& =\sum_{i=1}^{n} \pi_{i}\left(k \pi_{i}^{\alpha}-k \pi_{i}^{1+\alpha}\right)=\sum_{i=1}^{n} \pi_{i}\left(1-1+k \pi_{i}^{\alpha}-k \pi_{i}^{1+\alpha}\right)=\sum_{i=1}^{n} \pi_{i}\left(1-\frac{k}{k}+k \pi_{i}^{\alpha}-k \pi_{i}^{1+\alpha}\right) \\
& =\sum_{i=1}^{n} \pi_{i}-\sum_{i=1}^{n} \pi_{i} k\left(\frac{1}{k}-\pi_{i}^{\alpha}+\pi_{i}^{1+\alpha}\right)=1-\sum_{i=1}^{n} \pi_{i} k\left(\frac{1}{k}-\pi_{i}^{\alpha}+\pi_{i}^{1+\alpha}\right) .
\end{aligned}
$$

For the three-point distribution $(p, q, r)$ the discrete polarisation measure is

$$
D P(\alpha, k)^{(p, q, r)}=1-p k\left(1 / k-p^{\alpha}+p^{1+\alpha}\right)-q k\left(1 / k-q^{\alpha}+q^{1+\alpha}\right)-r k\left(1 / k-r^{\alpha}+r^{1+\alpha}\right) .
$$

For the alternative distribution $(p, \tilde{q})$ the DP index is

$$
D P(\alpha, k)^{(p, \tilde{q})}=1-p k\left(1 / k-p^{\alpha}+p^{1+\alpha}\right)-\tilde{q} k\left(1 / k-\tilde{q}^{\alpha}+\tilde{q}^{1+\alpha}\right) .
$$

where $q+r=\tilde{q}$.

Therefore

$$
\begin{aligned}
D P(\alpha, k)^{(p, \tilde{q})}-D P(\alpha, k)^{(p, q, r)}= & q k\left(1 / k-q^{\alpha}+q^{1+\alpha}\right)+r k\left(1 / k-r^{\alpha}+r^{1+\alpha}\right)-\tilde{q} k\left(1 / k-\tilde{q}^{\alpha}+\tilde{q}^{1+\alpha}\right) \\
= & q k\left(1 / k-q^{\alpha}+q^{1+\alpha}\right)+r k\left(1 / k-r^{\alpha}+r^{1+\alpha}\right)-(q+r) k\left(1 / k-\tilde{q}^{\alpha}+\tilde{q}^{1+\alpha}\right) \\
= & q k\left[\left(1 / k-q^{\alpha}+q^{1+\alpha}\right)-\left(1 / k-\tilde{q}^{\alpha}+\tilde{q}^{1+\alpha}\right)\right]+ \\
& +r k\left[\left(1 / k-r^{\alpha}+r^{1+\alpha}\right)-\left(1 / k-\tilde{q}^{\alpha}+\tilde{q}^{1+\alpha}\right)\right] .
\end{aligned}
$$

Define $h(\pi)=\left(1 / k-\pi^{\alpha}+\pi^{1+\alpha}\right)$. The first derivative of this function is

$$
h^{\prime}(\pi)=-\alpha \pi^{\alpha-1}+(1+\alpha) \pi^{\alpha}
$$

Notice that $h^{\prime}\left(\pi^{*}\right)=0$ when $\pi^{*}=\alpha /(1+\alpha)$. Evaluating at the first derivative we find that $h(\pi)$ is a strictly increasing for all $\pi>\pi^{*}$ and a strictly decreasing function for all $\pi<\pi^{*}$.

We can write the difference in DP when we merge two small groups in function of $h($.$) as$

$$
D P(\alpha, k)^{(p, \tilde{q})}-D P(\alpha, k)^{(p, q, r)}=q k[h(q)-h(\tilde{q})]+r k[h(r)-h(\tilde{q})] .
$$

We want to show that if $\alpha \geq 1$ then $h(q)>h(\tilde{q})$ and $h(r)>h(\tilde{q})$ for all $q, r<1 / 2$ and, therefore, $D P(\alpha, k)^{(p, \tilde{q})}-D P(\alpha, k)^{(p, q, r)}$ is positive for any distribution of $\mathrm{p}, \mathrm{q}$ and $\mathrm{r}$.

In principle we should analyse two possible cases: when the merger results in a group that is smaller than the original largest group $(\tilde{q} \leq p)$ and when the merger of the smallest groups has a result that is larger than the originally largest group $(\tilde{q}>p)$.

Case 1: $q+r=\tilde{q} \leq p$.

In this case $q+r=\tilde{q} \leq 1 / 2$ and $r \leq q<1 / 2$.

Since $\tilde{q}$ is smaller than $p$, then $\tilde{q} \leq 1 / 2$, Therefore we need that $h\left(\pi_{i}\right)>h(\tilde{q})$ for all $\pi_{i}<\tilde{q} \leq 1 / 2$.

Therefore if $h(q, r)>h(\tilde{q})$ for all $q, r \leq 1 / 2$, then $h(\pi)$ has to be a decreasing function for all $\pi \leq 1 / 2$. This is only possible if $\pi^{*}(\alpha) \geq 1 / 2$. But since $\pi^{*}=\alpha /(1+\alpha) \geq 1 / 2$, the latter is satisfied if and only if $\alpha \geq 1$. 
Therefore for $h$ being strictly decreasing for all $q, r \leq 1 / 2$, implies that the $D P$ index has to satisfy property 1 if $\alpha \geq 1$.

Case 2: $q+r=\tilde{q}>p$

In this case the minimum value for $p$ is, $p=1 / 3+\varepsilon$ and the maximum value for $\tilde{q}=2 / 3-\varepsilon$. Notice that now $q$ and $r$ cannot be any value between $(0,2 / 3)$, otherwise it would violate the assumption that $q, r<p$. Therefore, the maximum value for $q$ and $r$ is, $q=1 / 3, r=1 / 3-\varepsilon$. This is problematic because we do not need $h$ to be decreasing for $\pi \leq 2 / 3$.

Now for each value of $\tilde{q}$, which gives a value for $p$, there is a possible maximum value for $q$, which in the limit is $p$. Therefore what we need to show is that $h(\max q)>h(p) \geq h(\tilde{q})$,

We have to show therefore, that $h(\max q)>h(p) \geq h(\tilde{q})$ in all the rage of $\tilde{q} \in[1 / 2,2 / 3]$. This means that we have to analyse the range of possibilities when $1 / 3<q<1 / 2$ when $1 / 2 \leq \tilde{q}<2 / 3$

Notice that as $\tilde{q}$ decreases, then $p$ increases, and then the range of possible $q$ also increases; therefore in the limit the maximum $q=p$, increases. Therefore, if the following inequality $h(1 / 3+\varepsilon) \geq h(2 / 3-\varepsilon)$ is satisfied for all $\varepsilon$, this means that when $\tilde{q}>p$, then Property 1 is satisfied.

So we consider which families of $D P$ measures satisfy this inequality:

$$
\begin{aligned}
& h\left(\frac{1}{3}+\varepsilon\right) \geq h\left(\frac{2}{3}-\varepsilon\right), \\
& 1-\left(\frac{1}{3}+\varepsilon\right)^{\alpha}+\left(\frac{1}{3}+\varepsilon\right)^{1+\alpha} \geq 1-\left(\frac{2}{3}-\varepsilon\right)^{\alpha}+\left(\frac{2}{3}-\varepsilon\right)^{1+\alpha} \\
& \quad-\left(\frac{1}{3}+\varepsilon\right)^{\alpha}+\left(\frac{1}{3}+\varepsilon\right)^{1+\alpha} \geq-\left(\frac{2}{3}-\varepsilon\right)^{\alpha}+\left(\frac{2}{3}-\varepsilon\right)^{1+\alpha}, \\
& \left(\frac{1}{3}+\varepsilon\right)^{\alpha}\left(\frac{1}{3}+\varepsilon-1\right) \geq\left(\frac{2}{3}-\varepsilon\right)^{\alpha}\left(\frac{2}{3}-\varepsilon-1\right), \\
& \left(\frac{1}{3}+\varepsilon\right)^{\alpha}\left(-\frac{2}{3}+\varepsilon\right) \geq\left(\frac{2}{3}-\varepsilon\right)^{\alpha}\left(-\frac{1}{3}-\varepsilon\right), \\
& \left(\frac{\frac{1}{3}+\varepsilon}{\frac{2}{3}-\varepsilon}\right)^{\alpha} \geq\left(\frac{\frac{1}{3}+\varepsilon}{\frac{2}{3}-\varepsilon}\right) .
\end{aligned}
$$

Therefore in order for this inequality be satisfied for all values of $\varepsilon$ we need $\alpha \geq 1$. It would also be true for $r$, given that $r \leq q \leq 1 / 2$, and we have shown that $h$ is decreasing function of $\pi \leq 1 / 2$.

Therefore, $D P(\alpha, k)^{(p \tilde{q})} \geq D P(\alpha, k)^{(p, q, r)}$ if $\alpha \geq 1$.

Proof of necessity: By contradiction. We can show that if $\alpha<1$, then a distribution of $p, q, r$ can always exist such that the polarisation after merging the two smallest groups is smaller than the original, that is to say $D P(\alpha, k)^{(p \tilde{q})}<D P(\alpha, k)^{(p, q, r)}$.

Consider the case $q=r$. Therefore $\tilde{q}=2 q$.

Now compute,

$$
\begin{aligned}
& D P(\alpha, k)^{(p \tilde{q})}-D P(\alpha, k)^{(p, q, r)} \\
& =2 q\left[k\left(1 / k-q^{\alpha}+q^{1+\alpha}\right)\right]-k 2 q\left\{\left[1 / k-(2 q)^{\alpha}+(2 q)^{1+\alpha}\right]\right\} \\
& =2 k q\left[1 / k-q^{\alpha}+q^{1+\alpha}-1 / k+(2 q)^{\alpha}-(2 q)^{1+\alpha}\right] \\
& =2 k q\left[-q^{\alpha}+q^{1+\alpha}+(2 q)^{\alpha}-(2 q)^{1+\alpha}\right]
\end{aligned}
$$

We want to show that for $\alpha<1$, there always exists a set of $q \in\left(q^{*}, 1 / 3\right)$, such that $\left[-q^{\alpha}+q^{1+\alpha}+(2 q)^{\alpha}-(2 q)^{1+\alpha}\right]<0$,

(c) The Author(s). Journal compilation @ Royal Economic Society 2008 


$$
\begin{aligned}
& q^{\alpha}(q-1)+(2 q)^{\alpha}(1-2 q)<0, \\
& (2 q)^{\alpha}(1-2 q)<-q^{\alpha}(q-1), \\
& (2 q)^{\alpha}(1-2 q)<q^{\alpha}(1-q), \\
& \left(\frac{2 q}{q}\right)^{\alpha}<\frac{(1-q)}{(1-2 q)}, \\
& 2^{\alpha}<\frac{(1-q)}{(1-2 q)} .
\end{aligned}
$$

Notice that if $q=r$ then $q<1 / 3$. If $q=1 / 3$, then $(1-q) /(1-2 q)$ evaluated at $1 / 3$ is 2 .

Moreover, for $\alpha<1,2^{\alpha}<2$. Therefore, there always exists a set of $q^{\prime} \in\left(q^{*}, 1 / 3\right)$, such that $2^{\alpha}<\left(1-q^{\prime}\right) /\left(1-2 q^{\prime}\right)<2$.

Therefore, for any $\alpha<1$, there exist a set of $q^{\prime} \in\left(q^{*}, 1 / 3\right)$, such that $D P(\alpha, k)^{(p \tilde{q})}<D P(\alpha, k)^{(p, q, r)}$

\section{Proof of Theorem 2}

Proof of sufficiency: The general discrete polarisation index can be written as

$$
D P(\alpha, k)^{(N=n)}=1-\sum_{i=1}^{n} \pi_{i} k\left(1 / k-\pi_{i}^{\alpha}+\pi_{i}^{1+\alpha}\right) .
$$

For the two point distribution $(N=2)$ the discrete polarisation measure is

$$
\begin{aligned}
D P(\alpha, k)^{(N=2)} & =1-\sum_{i=1}^{2} \pi_{i} k\left(1 / k-\pi_{i}^{\alpha}+\pi_{i}^{1+\alpha}\right) \\
& =1-\pi_{1} k\left(1 / k-\pi_{1}^{\alpha}+\pi_{1}^{1+\alpha}\right)-\pi_{2} k\left(1 / k-\pi_{2}^{\alpha}+\pi_{2}^{1+\alpha}\right) .
\end{aligned}
$$

For the alternative $N$ point distribution $N=1+n$ the $D P$ index is

$$
\begin{aligned}
D P(\alpha, k)^{(N=n+1)} & =1-\sum_{i=1}^{n+1} \tilde{\pi}_{i} k\left(1 / k-\tilde{\pi}_{i}^{\alpha}+\tilde{\pi}_{i}^{1+\alpha}\right) \\
& =1-\tilde{\pi}_{1} k\left(1 / k-\tilde{\pi}_{1}^{\alpha}+\tilde{\pi}_{1}^{1+\alpha}\right)-\sum_{i=2}^{n+1} \tilde{\pi}_{i} k\left(1 / k-\tilde{\pi}_{i}^{\alpha}+\tilde{\pi}_{i}^{1+\alpha}\right)
\end{aligned}
$$

where $\tilde{\pi}_{1}=\pi_{1}$ and $\sum_{i=2}^{n+1} \tilde{\pi}_{i}=\pi_{2}$.

Therefore

$$
\begin{aligned}
D P(\alpha, k)^{(N=2)}-D P(\alpha, k)^{(N=n+1)}= & \sum_{i=2}^{n+1} \tilde{\pi}_{i} k\left(1 / k-\tilde{\pi}_{i}^{\alpha}+\tilde{\pi}_{i}^{1+\alpha}\right)-\pi_{2} k\left(1 / k-\pi_{2}^{\alpha}+\pi_{2}^{1+\alpha}\right) \\
= & \sum_{i=2}^{n+1} \tilde{\pi}_{i} k\left(1 / k-\tilde{\pi}_{i}^{\alpha}+\tilde{\pi}_{i}^{1+\alpha}\right)-\sum_{i=2}^{n+1} \tilde{\pi}_{i} k\left(1 / k-\pi_{2}^{\alpha}+\pi_{2}^{1+\alpha}\right) \\
= & \sum_{i=2}^{n+1} \tilde{\pi}_{i}\left[k\left(1 / k-\tilde{\pi}_{i}^{\alpha}+\tilde{\pi}_{i}^{1+\alpha}\right)-k\left(1 / k-\pi_{2}^{\alpha}+\pi_{2}^{1+\alpha}\right)\right] \\
= & \tilde{\pi}_{1}\left[k\left(1 / k-\tilde{\pi}_{1}^{\alpha}+\tilde{\pi}_{1}^{1+\alpha}\right)-k\left(1 / k-\pi_{2}^{\alpha}+\pi_{2}^{1+\alpha}\right)\right] \\
& +\tilde{\pi}_{2}\left[k\left(1 / k-\tilde{\pi}_{2}^{\alpha}+\tilde{\pi}_{2}^{1+\alpha}\right)-k\left(1 / k-\pi_{2}^{\alpha}+\pi_{2}^{1+\alpha}\right)\right]+\cdots \cdots . . \\
& +\tilde{\pi}_{n+1}\left[k\left(1 / k-\tilde{\pi}_{n+1}^{\alpha}+\tilde{\pi}_{n+1}^{1+\alpha}\right)-k\left(1 / k-\pi_{2}^{\alpha}+\pi_{2}^{1+\alpha}\right)\right] .
\end{aligned}
$$

Define $h(\pi)=\left(1 / k-\pi^{\alpha}+\pi^{1+\alpha}\right)$. The first derivative of this function is

$$
h^{\prime}(\pi)=-\alpha \pi^{\alpha-1}+(1+\alpha) \pi^{\alpha} .
$$

Notice that $h^{\prime}\left(\pi^{*}\right)=0$ when $\pi^{*}=\alpha /(1+\alpha)$. Evaluating at the first derivative we obtain that $h(\pi)$ is a strictly increasing for all the $\pi>\pi^{*}$ and a strictly decreasing function for all the $\pi<\pi^{*}$.

(c) The Author(s). Journal compilation (c) Royal Economic Society 2008 
We can write the difference in DP in function of $h(\cdot)$ as

$$
D P(\alpha, k)^{N=2}-D P(\alpha, k)^{N=n+1}=\sum_{i=2}^{n+1} \tilde{\pi}_{i}\left[h\left(\tilde{\pi}_{i}\right)-h\left(\pi_{2}\right)\right]
$$

We want to show that if $\alpha \geq 1$ then $h\left(\tilde{\pi}_{i}\right)>h\left(\pi_{2}\right)$ for all $\tilde{\pi}_{i}<1 / 2$ and, therefore, $D P(\alpha, k)^{N=2}-$ $D P(\alpha, k)^{N=n+1}$ is positive for any distribution.

In principle we should analyse two possible cases: when we split the small group $\left(\pi_{2} \leq \pi_{1}\right)$ and when we split the largest group $\left(\pi_{2}>\pi_{1}\right)$.

Case 1: If $\pi_{2} \leq \pi_{1}$.

In this case $\pi_{2} \leq 1 / 2$ and $\tilde{\pi}_{i}<1 / 2$.

Since $\pi_{2}$ is smaller than $\pi_{2}$, then $\pi_{2} \leq 1 / 2$, Therefore we need $h\left(\tilde{\pi}_{i}\right)>h\left(\pi_{2}\right)$ for all $\tilde{\pi}_{i}<\pi_{2} \leq 1 / 2$.

Therefore if $h\left(\tilde{\pi}_{i}\right)>h\left(\pi_{2}\right)$ for all $\tilde{\pi}_{i} \leq 1 / 2$, then $h(\pi)$ has to be a decreasing function for all $\pi \leq 1 / 2$. This is only possible if $\pi^{*}(\alpha) \geq 1 / 2$. But since $\pi^{*}=\alpha /(1+\alpha) \geq 1 / 2$, the latter is satisfied if and only if $\alpha \geq 1$.

Therefore for $h$ being strictly decreasing for all $\tilde{\pi}_{i} \leq 1 / 2$, this implies that the $D P$ index has to satisfy property 1 if $\alpha \geq 1$.

Case 2: $\pi_{2}>\pi_{1}$

In this case the maximum value that $\tilde{\pi}_{i}$ can take in the limit would be $\pi_{1}$, that is $\max \tilde{\pi}_{i}=\pi_{1}-\varepsilon$.

The value for $\pi_{2}=\left(1-\pi_{1}\right)$. Notice that now $\tilde{\pi}_{i}$ cannot be a value between $\left(0,1-\pi_{1}\right)$, otherwise this would violate the assumption that $\tilde{\pi}_{i}<\pi_{1}$. Therefore, the maximum value for $\tilde{\pi}_{i}$ is $\max \tilde{\pi}_{i}=\pi_{1}-\varepsilon$. This is problematic because we do not need $h$ to be decreasing for $\pi \leq \pi_{2}$.

Now for each value of $\pi_{2}$, which gives a value for $\pi_{1}$, there is a possible maximum value for $\tilde{\pi}_{i}$, which in the limit is $\pi_{1}$. Therefore what we need to show is that $h\left(\max \tilde{\pi}_{i}\right)>h\left(\pi_{1}\right) \geq h\left(\pi_{2}\right)$,

We have to show therefore, that $h\left(\max \pi_{1}\right)>h\left(\pi_{1}\right) \geq h\left(\pi_{2}\right)$ in all the range of $\pi_{2} \in\left(1 / 2,1-\pi_{1}\right]$. This means that we have to analyse the range of possibilities when $\pi_{1}<\hat{\pi}_{i}<1 / 2$ when $1 / 2 \leq \pi_{2}<1-\pi_{1}$

Notice that as $\pi_{2}$ decreases, then $\pi_{1}$ increases, and then the range of possible $\tilde{\pi}_{i}$ also increases, and therefore $\max \tilde{\pi}_{i}$ (that in the limit $=\pi_{1}$ ) also increases. Therefore, if the following inequality $h\left(\pi_{1}+\varepsilon\right) \geq h\left(1-\pi_{1}-\varepsilon\right)$ is satisfied for all $\varepsilon$, this means that when $\pi_{2}>\pi_{1}$, Property 1 is satisfied.

So we look which families of $D P(\alpha, k)$ measures satisfies this inequality:

$$
\begin{aligned}
& h\left(\pi_{1}+\varepsilon\right) \geq h\left(1-\pi_{1}-\varepsilon\right), \\
& 1-\left(\pi_{1}+\varepsilon\right)^{\alpha}+\left(\pi_{1}+\varepsilon\right)^{1+\alpha} \geq 1-\left(1-\pi_{1}-\varepsilon\right)^{\alpha}+\left(1-\pi_{1}-\varepsilon\right)^{1+\alpha} \\
& \quad-\left(\pi_{1}+\varepsilon\right)^{\alpha}+\left(\pi_{1}+\varepsilon\right)^{1+\alpha} \geq-\left(1-\pi_{1}-\varepsilon\right)^{\alpha}+\left(1-\pi_{1}-\varepsilon\right)^{1+\alpha} \\
& \left(\pi_{1}+\varepsilon\right)^{\alpha}\left(\pi_{1}+\varepsilon-1\right) \geq\left(1-\pi_{1}-\varepsilon\right)^{\alpha}\left(1-\pi_{1}-\varepsilon-1\right) \\
& \left(\pi_{1}+\varepsilon\right)^{\alpha}\left(\pi_{1}+\varepsilon-1\right) \geq\left(1-\pi_{1}-\varepsilon\right)^{\alpha}\left(-\pi_{1}-\varepsilon\right) \\
& \left(\frac{\pi_{1}+\varepsilon}{1-\pi_{1}-\varepsilon}\right)^{\alpha} \geq\left(\frac{\pi_{1}+\varepsilon}{1-\pi_{1}-\varepsilon}\right) .
\end{aligned}
$$

Therefore in order for this inequality be satisfied for all values of $\varepsilon$ we need that $\alpha \geq 1$. Moreover it would also be true for all $\tilde{\pi}_{i} \leq \max \tilde{\pi}_{i}$ given that we have shown that $h$ is a decreasing function of $\pi$.

Therefore, $D P(\alpha, k)^{N=2} \geq D P(\alpha, k)^{N=n+1}$ if $\alpha \geq 1$.

Proof of necessity: By contradiction. We can show that if $\alpha<1$, then a distribution of $\pi$ always exists such that the polarisation before splitting one group is smaller than the new distribution, that is to say $D P(\alpha, k)^{(N=2)}<D P(\alpha, k)^{(N=N+1)}$. 
Consider the case where the distribution among two groups is composed of $\pi_{1}$ and $\pi_{2}$. Then the distribution of $N+1$ groups is composed of $\pi_{1}$ and $\tilde{\pi}_{2}=\tilde{\pi}_{3}=\tilde{\pi}_{4}=\cdots=\tilde{\pi}_{N+1}=\pi$, such that $\sum_{i=2}^{N+1} \tilde{\pi}_{i}=N \pi=\pi_{2}$.

Now compute,

$$
\begin{aligned}
& D P(\alpha, k)^{(2)}-D P(\alpha, k)^{(N+1)} \\
& =N \pi\left(k\left(1 / k-\pi^{\alpha}+\pi^{1+\alpha}\right)\right]-k \pi_{2}\left(1 / k-\pi_{2}^{\alpha}+\pi_{2}^{1+\alpha}\right) \\
& =N \pi\left(k\left(1 / k-\pi^{\alpha}+\pi^{1+\alpha}\right)\right]-k(N \pi)\left[1 / k-(N \pi)^{\alpha}+(N \pi)^{1+\alpha}\right] \\
& =N \pi k\left[1 / k-\pi^{\alpha}+\pi^{1+\alpha}-1 / k+(N \pi)^{\alpha}-(N \pi)^{1+\alpha}\right] \\
& =N \pi k\left[-\pi^{\alpha}+\pi^{1+\alpha}+(N \pi)^{\alpha}-(N \pi)^{1+\alpha}\right] .
\end{aligned}
$$

We want to show that for $\alpha<1$, a set of $\pi \in\left(\pi^{* *}, 1 / N\right)$ always exists such that $N \pi k\left[-\pi^{\alpha}+\pi^{1+\alpha}+(N \pi)^{\alpha}-(N \pi)^{1+\alpha}\right]<0$, that $-\pi^{\alpha}+\pi^{1+\alpha}+(N \pi)^{\alpha}-(N \pi)^{1+\alpha}<0$,

$$
\begin{aligned}
& \pi^{\alpha}(\pi-1)+(N \pi)^{\alpha}(1-N \pi)<0, \\
& (N \pi)^{\alpha}(1-N \pi)<-\pi^{\alpha}(\pi-1), \\
& (N \pi)^{\alpha}(1-N \pi)<\pi^{\alpha}(1-\pi), \\
& \left(\frac{N \pi}{\pi}\right)^{\alpha}<\frac{(1-\pi)}{(1-2 \pi)}, \\
& N^{\alpha}<\frac{(1-\pi)}{(1-N \pi)} .
\end{aligned}
$$

Notice that if $\tilde{\pi}_{2}=\tilde{\pi}_{3}=\tilde{\pi}_{4}=\cdots=\tilde{\pi}_{N+1}=\pi$, then $\pi<1 /(N+1)$. If $\pi=1 /(N+1)$, then $(1-\pi) /(1-N \pi)$ evaluated at $1 /(N+1)$ is $N$.

Moreover, for $\alpha<1, N^{\alpha}<N$.Therefore, there always exist a set of $\pi^{\prime} \in\left(\pi^{* *}, 1 /(N+1)\right)$, such that $N^{\alpha}<\left(1-\pi^{\prime}\right) /\left(1-N \pi^{\prime}\right)<N$.

Therefore, for any $\alpha<1$, a set of $\pi^{\prime} \in\left(\pi^{* *}, 1 /(N+1)\right)$ always exists such that $D P(\alpha, k)^{(N=2)}$ $<D P(\alpha, k)^{(N=N+1)}$.

\section{Proof of Lemma 1}

Step 1: Suppose there are $N$ groups of any size. Take the biggest one and separate it from the others. Then merge all the other groups into one group. By Property $1 b$ the $D P$ measure increases if and only if $\alpha \geq 1$. That is, in the new distribution the index is larger than in the original one if and only if $\alpha \geq 1$. This means that, given any distribution of $N$ groups, we can always find another distribution on two groups where the DP index is larger if and only if $\alpha \geq 1$. This does not mean that the new distribution is more polarise as explained above but that the index is larger.

Step 2: Suppose now that we only have two groups of $\pi$ and $(1-\pi)$ sizes. The polarisation index

$$
D P=k \sum_{i=1}^{2} \pi_{i}^{1+\alpha}\left(1-\pi_{i}\right)=k\left[\pi_{1}^{1+\alpha}\left(1-\pi_{1}\right)+\left(1-\pi_{1}\right)^{1+\alpha} \pi_{1}\right] .
$$

It is easy to verify that for any $\alpha$ this expression is maximised at $\pi_{1}=\pi_{2}=0.5$, which means that this is a global maximum if $\alpha \geq 1$.

\section{Proof of Theorem 3}

Any three point discrete distribution can be written in the form $(x, 1-2 x, x)$ such that $x \in[0,1 / 2]$. Our purpose is to show under what conditions $D P$ is an increasing function of $x$, the shifted mass from the $q$ group to any other group,

$$
D P(x, 1-2 x, x)<D P(\tilde{x}, 1-2 \tilde{x}, \tilde{x}) \text { for all } x<\tilde{x} .
$$

(C) The Author(s). Journal compilation (C) Royal Economic Society 2008 
Therefore the comparison of $D P(p, q, p)$ and $D P(p+x, q-2 x, p+x)$ would be the same as the comparison of

$$
D P\left(x^{\prime}, 1-2 x^{\prime}, x^{\prime}\right) \text { and } D P(\tilde{x}, 1-2 \tilde{x}, \tilde{x}) \text { where } x^{\prime}=p \text { and } \tilde{x}=p+x .
$$

We can compute $D P$ in this case as

$$
D P(\alpha, k)=k\left[2 x^{1+\alpha}(1-x)+(1-2 x)^{1+\alpha} 2 x\right]=k\left[2 x^{1+\alpha}-2 x^{2+\alpha}+(1-2 x)^{1+\alpha} 2 x\right] .
$$

The first derivative of $D P$ is

$$
\begin{aligned}
\partial D P / \partial x(\alpha, k) & =k\left[2(1+\alpha) x^{\alpha}-2(2+\alpha) x^{1+\alpha}+(1+\alpha)(1-2 x)^{\alpha}(-2) 2 x+(1-2 x)^{1+\alpha} 2\right] \\
& =2 k\left\{x^{\alpha}[(1+\alpha)-(2+\alpha) x]+(1-2 x)^{\alpha}[-2(1+\alpha) x+(1-2 x)]\right\} \\
& =2 k\left\{x^{\alpha}(1+\alpha-2 x-x \alpha)+(1-2 x)^{\alpha}[(1-2 x)-2 x-2 x \alpha]\right\} .
\end{aligned}
$$

Therefore $\partial D P / \partial x$ evaluated at $\alpha=1$ is always positive given that $\partial D P(1, k) / \partial x=$ $2 k(1-3 x)^{2}>0 \forall x$. Therefore if $\alpha=1$ then $\partial D P(1, k) / \partial x>0$ for any distribution.

In addition the partial derivative, $\partial D P(\alpha, k) / \partial x$, evaluated at $x=\frac{1}{3}$ is always equal to 0

$$
\begin{aligned}
& 2 k\left\{\left(\frac{1}{3}\right)^{\alpha}\left(1+\alpha-2 \frac{1}{3}-\frac{1}{3} \alpha\right)+\left(1-2 \frac{1}{3}\right)^{\alpha}\left[\left(1-2 \frac{1}{3}\right)-2 \frac{1}{3}-2 \frac{1}{3} \alpha\right]\right\} \\
& =k\left[\left(\frac{1}{3}\right)^{\alpha}\left(\frac{1}{3}+\frac{2}{3} \alpha\right)+\left(\frac{1}{3}\right)^{\alpha}\left(-\frac{1}{3}-\frac{2}{3} \alpha\right)\right]=0 \text { for all values of } \alpha .
\end{aligned}
$$

The second derivative is

$$
\begin{aligned}
\partial^{2} D P(\alpha, k) / \partial x \partial x= & 2 k\left\{\alpha x^{\alpha-1}[(1+\alpha)-2 x-x \alpha]+x^{\alpha}(-2-\alpha)+\right. \\
& \left.+\alpha(1-2 x)^{\alpha-1}(-2)(1-4 x-2 x \alpha)+(1-2 x)^{\alpha}(-4-2 \alpha)\right\} \\
= & 2 k\left[\alpha x^{\alpha-1}(1+\alpha-2 x-x \alpha)-x^{\alpha}(2+\alpha)-\right. \\
& \left.-2 \alpha(1-2 x)^{\alpha-1}(1-4 x-2 x \alpha)-(1-2 x)^{\alpha}(4+2 \alpha)\right] .
\end{aligned}
$$

Evaluating the second derivative at $x=1 / 3$ we obtain

$$
\partial^{2} D P(\alpha, k) / \partial x \partial x=\left(\frac{1}{3}\right)^{\alpha}\left[3\left(2 \alpha^{2}-2\right)\right] .
$$

This means that for $\alpha=1$, then $\partial^{2} D P(1, k) / \partial x \partial x=0$, which implies that $x=1 / 3$ is an inflection point. However if $\alpha<1$, then $\partial^{2} D P(\alpha, k) / \partial x \partial x<0$, which means that $x=1 / 3$ is a maximum and if $\alpha<1$, then $\partial^{2} D P(\alpha, k) / \partial x \partial x>0$, which means that $x=1 / 3$ is a minimum. Therefore if $x=1 / 3$ is a maximum, this means that for any ball around $x=1 / 3, D P(\alpha<1, k)^{x=1 / 3+\varepsilon}<D P(\alpha<1, k)^{x=1 / 3}$ which violates property 2 . On the other hand for $\alpha>1, x=1 / 3$ is a minimum which implies that $D P(\alpha>1, k)^{x=1 / 3-\varepsilon}>D P(\alpha>1, k)^{x=\frac{1}{3}}$ which also violates Property 2 . Therefore the only DP measure that satisfies property 3 for any distribution has a parameter $\alpha=1$.

\section{A.2. Operational Criteria to Define Genocides}

(1) Authorities' complicity in mass murder must be established. Any persistent, coherent pattern of action by the state and its agents, or by a dominant social group, that brings about the destruction of a people's existence, in whole or in part, within the effective territorial control of a ruling authority is prima facie evidence of that state, or other, authority's responsibility. In situations of civil war (i.e., contested territorial control) either of the contending authorities may be deemed responsible for carrying out, or allowing, such actions.

(2) The physical destruction of a people requires time to accomplish: it implies a persistent, coherent pattern of action. Thus, only sustained episodes that last six months or more are included in the final dataset. This six month requirement is to a degree arbitrary. At

(C) The Author(s). Journal compilation (C) Royal Economic Society 2008 
the other end of the time spectrum are episodic attacks on a group that recur periodically, such as Iraqi government attacks on Kurds from 1960 to 1975. Annual codings are especially important for these kinds of episodes to permit tracking of peaks and lulls.

(3) The victims to be counted are unarmed civilians not combatants. It rarely is possible to distinguish precisely between the two categories in the source materials. Certain kinds of tactics nonetheless are indicative of authorities' systematic targeting of noncombatants: massacres, unrestrained bombing and shelling of civilian inhabited areas, declaration of free fire zones, starvation by prolonged interdiction of food supplies, forced expulsion ('ethnic cleansing') accompanied by extreme privation, killings etc.

(4) In principle, numbers provided in 'body counts' do not enter the definition of what constitutes an episode. A 'few hundred' killed constitutes as much a genocide or politicide as the deaths of thousands if the victim group is small in number to begin with.

Note. Definitions and operational guidelines are adapted from Harff and Gurr (1996).

\section{A.3. Definition of the Variables and Sources of Information}

GENOCIDE: The data set we use comes from Gurr and Harff (1995) and Harff (2003) and is available by in the The State Failure task force project. This is the only academically recognised dataset on genocides and politicide

$C W$ : A dummy hat takes value 1 if there is a civil war during the period and zero otherwise. The data come from Uppsala/PRIO.

LGDPC: $\log$ of real GDP per capita of the initial period (1985 international prices) from the Penn World Tables 5, 6.

LNPOP: $\log$ of the population at the beginning of the period from the Penn World Tables 5, 6 . PRIMEXP: Proportion of primary commodity exports of GDP. Primary commodity exports (Collier and Hoeffler, 2001).

MOUNTAINS: Percentage of Mountainous Terrain: This variable is based on work by geographer A.J Gerard for the World Bank's 'Economics of Civil war, Crime, and Violence' project.

NONCONT: Non-contiguous state: countries with territory holding at least 10,000 people and separated from the land area containing the capital city either by land or by 100 kilometres of water were coded as 'noncontiguous'. (Fearon and Laitin, 2003)

DEMOCRACY: Democracy score: general openness of the political institutions $(0=$ low; $10=$ high). Polity III data set. (http://weber.ucsd.edu/ kgledits/Polity.html). We transform the score into a dummy variable that takes the value 1 if the score is higher or equal to 4 . This variable is highly correlated with the variable Freedom of the Freedom House.

ETHFRAC: index of ethnolinguistic fractionalisation calculated using data from the World Christian Encyclopedia.

ETHPOL: index of ethnolinguistic polarisation calculated using the data of the World Christian Encyclopedia.

ETHDOM: ethnic dominance. It takes the value 1 if an ethnic group represents between $45 \%$ and $90 \%$ of the total population following the suggestion of Collier (2001) and Collier and Hoeffler (2004). It is calculated using data from the World Christian Encyclopedia

Universitat Pompeu Fabra (Barcelona GSE) and Universitat Pompeu Fabra (Barcelona GSE), CEPR and CESifo

Universitat Pompeu Fabra (Barcelona GSE) and Universitat Pompeu Fabra (Barcelona GSE), Instituto Valenciano de Investigaciones Economicas

Submitted: 27 January 2006

Accepted: 6 February 2008

(C) The Author(s). Journal compilation (C) Royal Economic Society 2008 


\section{References}

Aghion, P., Alesina, A. and Trebbi, F. (2004). 'Endogenous political institutions', Quarterly Journal of Economics, vol. 119(2) (May), pp. 565-612.

Alesina, A., Devleeschauwer, A., Easterly, W., Kurlat, S. and Wacziarg, R. (2003). 'Fractionalisation', Journal of Economic Growth, vol. 8(2) (June), pp. 155-94.

Anderson, G. (2004). 'Toward an empirical analysis of polarisation', Journal of Econometrics, vol. 122(1) (September), pp. 1-26.

Atlas Narodov Mira (Atlas of the People of the World) (1964). (S.I. Bruck and V.S. Apenchenko, eds.), Moscow: Glavnoe Upravlenie Geodezii i Kartografii.

Barret, D. ed. (1982). World Christian Encyclopedia, Oxford: Oxford University Press.

Caselli, F. and Coleman, J. (2006). 'On the theory of ethnic conflict', NBER Working Paper No. 12125.

Collier, P. (2001). 'Implications of ethnic diversity', Economic Policy, vol. 16(32) (April), pp. 127-66.

Collier, P. and Hoeffler, A. (2004). 'Greed and grievances in civil wars', Oxford Economic Papers, vol. 56(4) (October), pp. 563-95.

Duclos, J., Esteban, J. and Ray, D. (2004). 'Polarisation: concept, measurement and estimation', Econometrica, vol. 74(6) (November), pp. 1737-72.

Easterly, W. and Levine, R. (1997). 'Africa's growth tragedy: policies and ethnic divisions', Quarterly Journal of Economics, vol. 112(4) (November), pp. 1203-50.

Easterly, W., Gatti, R. and Kurlat, S. (2006). 'Development, democracy and mass killings', Journal of Economic Growth, vol. 11(2) (June), pp. 129-56.

Encyclopedia Britannica (2002). Chicago: Encyclopedia Britannica.

Esteban, J. and Ray, D. (1994). 'On the measurement of polarisation', Econometrica, vol. 62(4) (July), pp. 81951.

Fearon, J. (2003). 'Ethnic and cultural diversity by country', Journal of Economic Growth, vol. 8(2) (June), pp. 195-222.

Fearon J. and Laitin, D. (2003). 'Ethnicity, insurgency, and civil war', American Political Science Review, vol. 97(1) (February), pp. 75-90.

Gradin, C. (2000). 'Polarisation by subpopulations in Spain: 1973-91', Review of Income and Wealth, vol. 46(4) (December), pp. 457-74.

Harff, B. (2003). 'No lessons learned from holocaust? Assessing risks of genocide and political mass murder since 1955', American Political Science Review, vol. 97(1) (February), pp. 57-73.

Harff, B. and Gurr, T. R. (1996). 'Victims of the state: genocides, politicides, and group repression from 1945 to 1995', in (A.J. Jongman, ed.), Contemporary Genocides: Causes, Cases, Consequences, pp. 33-58, Leiden: University of Leiden, PIOOM Interdisciplinary Research Programme on Root Causes of Human Rights Violations.

Horowitz, D. (1985). Ethnic Groups in Conflict, Berkeley: University of California Press.

Keefer, P. and Knack, S. (2002). 'Polarisation, politics and property rights: links between inequality and growth', Public Choice, vol. 111(1-2) (April), pp. 127-54.

Mauro, P. (1995). 'Corruption and growth', Quarterly Journal of Economics, vol. 110(3) (August), pp. 681712.

Montalvo, J.G. and Reynal-Querol, M. (2005a). 'Ethnic polarisation, potential conflict, and civil wars', American Economic Review, vol. 95(3) (June), pp. 796-816.

Montalvo, J.G. and Reynal-Querol, M. (2005b). 'Ethnic diversity and economic development', Journal of Development Economics, vol. 76, pp. 293-323.

Reynal-Querol, M. (2001). 'Religious conflict and growth', chapter 1 of PhD thesis, LSE, London.

Reynal-Querol, M. (2002). 'Ethnicity, political systems, and civil wars', Journal of Conflict Resolution, vol. 46(1) (February), pp. 29-54.

Singer, J.D. and Small, M. (1994). 'Correlates of war project: international and civil war data, 1816-1992'. (ICPSR 9905), Ann Arbor, Michigan.

Taylor, C. and Hudson, M.C. (1972). The World Handbook of Political and Social Indicators, 2nd edn, New Haven, CT: Yale University Press.

Vanhaven, T. (1999). 'Domestic ethnic conflict and ethnic nepotism: a comparative analysis', Journal Of Peace Research, vol. 36(1) (January), pp. 55-73.

Wolfson, M.C. (1994). 'When inequalities diverge', American Economic Review, vol. 84(2) (May) (Papers and Proceedings), pp. 353-8.

World Factbook (several years). Washington: Central Intelligence Agency. 